NBER WORKING PAPER SERIES

\title{
LONG-TERM CONSEQUENCES OF VIETNAM-ERA CONSCRIPTION: SCHOOLING, EXPERIENCE, AND EARNINGS
}

\author{
Joshua D. Angrist \\ Stacey H. Chen \\ Working Paper 13411 \\ http://www.nber.org/papers/w13411
NATIONAL BUREAU OF ECONOMIC RESEARCH
1050 Massachusetts Avenue
Cambridge, MA 02138
September 2007

This study was conducted while the authors were Special Sworn Status researchers of the U.S. Census Bureau at the Boston Research Data Center. Research results and conclusions expressed are those of the authors and do not necessarily reflect the views of the Census Bureau. This paper has been screened to insure that no confidential data are revealed. Special thanks got to B.K. Atrostic, Jim Davis, and Brian Holly for help with the data used in this study. Thanks also go to Brigham Frandsen and Simone Schaner for outstanding research assistance and to David Autor, Mark Duggan, Amy Finkelstein, Jerry Hausman, Whitney Newey, Sarah Turner, Steve Pischke, and participants in the Summer 2007 Labor Studies Meeting for helpful discussions and comments. We gratefully acknowledge funding from the National Science Foundation. The views expressed herein are those of the author(s) and do not necessarily reflect the views of the National Bureau of Economic Research.

(C) 2007 by Joshua D. Angrist and Stacey H. Chen. All rights reserved. Short sections of text, not to exceed two paragraphs, may be quoted without explicit permission provided that full credit, including (C) notice, is given to the source. 
Long-term consequences of vietnam-era conscription: schooling, experience, and earnings Joshua D. Angrist and Stacey H. Chen

NBER Working Paper No. 13411

September 2007

JEL No. I18,I22,J24,J31

\section{$\underline{\text { ABSTRACT }}$}

This paper uses the 2000 Census 1-in-6 sample to look at the long-term impact of Vietnam-era military service. Instrumental Variables estimates using draft-lottery instruments show post-service earnings losses close to zero in 2000, in contrast with earlier results showing substantial earnings losses for white veterans in the 1970s and 1980s. The estimates also point to a marked increase in schooling that appears to be attributable to the Vietnam-era GI Bill. The net wage effects observed in the 2000 data can be explained by a flattening of the experience profile in middle age and a modest return to the increased schooling generated by the GI Bill. Evidence on disability effects is mixed but seems inconsistent with a long-term effect of Vietnam-era military service on health.

Joshua D. Angrist

Department of Economics

MIT, E52-353

50 Memorial Drive

Cambridge, MA 02142-1347

and NBER

angrist@mit.edu

Stacey H. Chen

412 NBER

1050 Mass Ave

Cambridge, MA 02138

USA

schen@albany.edu 


\section{Introduction}

Economists had a pivotal role in formulating the intellectual case against the draft. The core of this argument is that conscription amounts to a hidden tax on soldiers, with the further disadvantage of uncertainty as to who will have to pay (see, e.g., Oi, 1967). This negative view of the draft notwithstanding, WWII veterans typically have somewhat better civilian outcomes than same-age non-veterans, while Vietnam era veterans do only a little worse. ${ }^{1}$ A fundamental difficulty with these simple comparisons, however, is selection bias. The process of screening for military service generates a pool of veterans that differs in important ways from non-veterans. For example, in a comparison of the civilian mortality risk of WWII veterans with others from the same cohorts, WWII veterans had lower death rates, primarily due to a reduced risk of deaths from disease (Seltzer and Jablon, 1974). Although military service may impart some benefits, increased longevity seems likely to be an artifact of health-related selection bias.

Although not as obvious as the selection bias inherent in mortality comparisons, selection bias is also a concern in studies of the economic effects of the draft. The military enlistment process selects soldiers on the basis of factors related to earnings potential in at least two ways. On one hand, the military prefers high school graduates, and screens out those with very low test scores. As a result, men with very low earnings potential are unlikely to end up as soldiers. ${ }^{2}$ On the other hand, some potential recruits find military service attractive precisely because their prospects in the civilian labor market are poor, while those with the highest earnings potential probably find it worthwhile to work hard to escape the draft. The net selection bias in this case is unclear.

The draft lottery provides an opportunity to overcome the problem of selection bias in estimates of the consequences of Vietnam-era military service. From 1970-72, induction priority was determined by a series of lotteries in which cohorts at risk of conscription were assigned random sequence numbers (RSNs) from 1-365. Men were then called for pre-induction processing from lowest-to-highest, up to a ceiling. Because draft lottery numbers are highly correlated with veteran status, and probably uncorrelated with other factors related to earnings, lottery RSNs can be used to construct instrumental variables (IV) estimates of the causal effect of Vietnam-era conscription on variables like civilian

\footnotetext{
${ }^{1}$ See, for example, studies of veteran effects cited in Angrist and Krueger (1994). Henderson (2005) reviews the role of economists in ending the draft.

${ }^{2}$ See, e.g., Eitelberg et al. (1984).
} 
earnings, educational attainment, and health.

Angrist (1990) used the draft lottery to construct IV estimates of the effect of compulsory military service on civilian earnings through 1984. These estimates show substantial earnings losses for white veterans - as much as 15 percent of average civilian earnings in the cohort. ${ }^{3}$ Angrist (1990) argued that the time series pattern of estimated earnings losses is explained by lost labor market experience. In particular, estimates of a log-quadratic potential-experience model suggest military service generates earnings losses equivalent to roughly two years of lost experience, the period of service for draftees. An implication of the loss-of-experience story is that Vietnam-era draftees should eventually catch up with same-age non-veterans, though they had not done so by 1984, when the draft-lottery cohorts were in their early-to-mid thirties.

The empirical analysis in this paper begins with new estimates of the long-term effects of Vietnam-era service. The 2000 Census long form, which collects information on exact dates of birth, provides an opportunity to look at the economic and other consequences of Vietnam-era conscription as the draft-lottery cohorts approach age $50 .{ }^{4}$ In addition to earnings and other labor market variables, we look at schooling and disability status. Schooling is especially interesting in this context because of the GI Bill, widely believed to be a driving force in the expansion of American higher education. Vietnam veterans had access to GI Bill benefits similar to those made available to veterans of WWII and Korea. Disability status is important because Vietnam-era service may be linked to a number of health problems, most notably Post-Traumatic Stress Disorder (PTSD) and conditions that have been related to the Agent Orange herbicide.

In addition to directly estimating the long-term impact of Vietnam-era conscription, we offer an interpretation of schooling and earnings effects using a Mincer-style wage equation. Our interpretation is motivated by two findings. First, the earnings results (and the effects on other labor market variables such as employment) are nearly zero, consistent with the overtaking age of about 50 estimated for veterans in Angrist (1990). Second, the 2000 Census data show a marked impact of Vietnam-era conscription on schooling, with effects of a magnitude similar to those reported in studies of the WWII and Korean-era GI Bills (Bound and Turner, 2002; Stanley, 2003). We argue that the net wage effects

\footnotetext{
${ }^{3}$ Angrist (1989) estimated larger though imprecise effects on white veteran's wages using a smaller sample. Estimates for nonwhites are not significantly different from zero in either the 1989 and or 1990 studies.

${ }^{4}$ Although birthday information is not made publicly available, we have used it through an agreement with the Census Bureau's Center for Economic Studies.
} 
observed in the 2000 data can be explained by a flattening of the experience profile in middle age and a modest return to the post-service schooling paid for by veterans benefits. ${ }^{5}$ Adjusting the wage estimates for possible health consequences of military service matters little for this story.

\section{Data and First-Stage}

\subsection{The 2000 Census 1-in-6 File}

The 2000 Census long form sample includes approximately one-sixth of US households. ${ }^{6}$ For the purposes of this study, we created an extract of US-born men residing in the 50 States and the District of Columbia, born between 1948 and 1953 or in subsets of these birth years. The cohorts of 19-year-olds at risk of conscription in the draft lotteries were born from 1950-52 so our analysis focuses on the sample of men in this group. This sample includes about 700,000 whites and 96,000 nonwhites. There is a smaller but non-negligible draft-lottery impact on men born in 1948 and 1949, so estimates are also reported for an expanded sample of men born 1948-52. The 1948-52 sample includes more than 1.14 million whites and about 155,000 nonwhites. Finally, although no one born after 1952 was drafted, men born in 1953 were assigned RSNs and a few volunteered in anticipation of possible conscription. We therefore report first-stage estimates for the 1953 cohort.

Roughly 24 percent of men born 1950 to 1952 served in the Vietnam era and about 38 percent were draft-eligible. These and other descriptive statistics appear in Table 1, which reports means by veteran status and race for the 1950-52 sample. White veterans from these cohorts have lower employment rates and earnings than white non-veterans, while the pattern is reversed for nonwhites. For example, the annual 1999 earnings of white veterans was about $\$ 39,500$, while white non-veterans earned $\$ 48,500$ that year.

\footnotetext{
${ }^{5}$ The first attempt to estimate the returns to veterans post-service schooling is Griliches and Mason (1972), who report results for a sample of WWII veterans from the 1964 CPS.

${ }^{6}$ The 1-in-6 long form sample is the basis for the publicly available PUMS files. These files, documented in US Census Bureau (2005), are simple random samples drawn from the 1-in-6 file, though the 1-in-6 file is not a simple random sample from the census sampling frame. Rather, the Census Bureau reduces the sampling rate in more densely populated areas. Adjustment for variation in sampling rates is made here by using the weighting variables that are included in the long-form file. These weights adjust for non-response as well as for non-random sampling, and are designed to match external population totals by age, race, sex and Hispanic origin. In practice, weighting matters little for our results. We also confirmed that the means from publicly available data from the 1-in- 6 file are close to those from the 5 percent file distributed through IPUMS. The original 2000 long form sample includes Puerto Rico and island territories; residents of these areas are omitted from our study.
} 
Unemployment rates are low in both the veteran and non-veteran groups, but many men, especially nonwhites, were out of the labor force.

Overall, the average schooling level in the sample is 13.8 years for whites and 12.6 years for nonwhites. The average years of college is 1.73 for whites and 1.02 for nonwhites. $^{7}$ The contrast in average educational attainment by veteran status parallels that in earnings, with white veterans obtaining less schooling and non-white veterans obtaining more schooling than their non-veteran counterparts. On the other hand, although white veterans are less likely to have attended or completed one or more years of college, they are more likely than non-veterans to be high school graduates. For non-whites, the schooling differential by veteran status changes in favor of non-veterans at the BA level or higher.

A large number of men born in 1950-52 report having a work-related disability about 12 percent of whites and 21 percent of nonwhites. The proportion reporting other disabilities, but no disability related to work, is 7 percent for whites and 12 percent for nonwhites. The work and non-work disability variables used here are mutually exclusive. Thus, a total of 19 percent of whites and 33 percent of nonwhites are affected by some kind of disability (i.e., the sum of work and non-work disability rates). ${ }^{8}$ White veterans have somewhat higher disability rates than non-veterans, while disability rates differ little by veteran status for nonwhites.

Veterans below the age of 65 are eligible for two types of disability payments, servicerelated veterans disability compensation (VDC) and means-tested military disability pensions (MDP) for disabled low-income veterans. We therefore examine the effects of Vietnam-era service on two disability-related income variables: an "other income" variable

\footnotetext{
${ }^{7}$ Highest grade completed (HGC) was imputed from the categorical Census schooling variable using Jaeger (1997). Years of college ranges from 0-4 and was constructed from imputed HGC as $\operatorname{Min}(\operatorname{Max}($ HGC-12,0), 4), similar to Bound and Turner (2002).

${ }^{8}$ The disability variables used here come from two questions on disabilities by type. Respondents were asked: [Question 17] "Because of a physical, mental, or emotional condition lasting 6 months or more, does this person have any difficulty in doing any of the following activities: (a) learning, remembering or concentrating (b) dressing, bathing or getting around inside the home (c) going outside the home alone to shop or visit a doctor's office (d) working at a job or business?" The previous question [16] asks "Does this person have any of the following long-lasting conditions: (a) Blindness, deafness, or a severe vision or hearing impairment (b) A condition that substantially limits one or more basic physical activities such as walking, climbing stairs, reaching, lifting, or carrying?" We coded a work-related disability for those who answered yes to (17d). Other disabilities were coded as follows: (16a) vision or hearing; (16b) physical; (17a) mental; (17b) self-care; (17c) mobility. Respondents can have more than one disability. We coded a non-work disability for anyone who responded yes to 16a, 16b, 17a, 17b, or 17c, i.e., they indicated some disability, but no work-related disability $(17 \mathrm{~d})$. We define the presence of any disability by the sum of the work-related and non-work disability indicators.
} 
that includes VDC, and a non-Social-Security (SSA) "retirement and disability pension" variable that includes MDP and regular military pensions. ${ }^{9}$ Table 1 shows much higher amounts of disability-related income for veterans. This is almost certainly due to veterans receiving VDC and MDP. In contrast, differences in SSDI and SSI amounts by veteran status (not reported) are much smaller.

Table 1 focuses on men born 1950-52 because these cohorts were most affected by the draft lottery. As noted above, however, we also present results for an expanded sample of men born 1948-52. Descriptive statistics for the 1948-52 sample and means by single year of birth appear in Appendix Tables A1 and A2. The 1948 and 1949 cohorts were more likely to serve in the Vietnam era than the 1950-52 group, with Vietnam-era service rates peaking at 45 percent for whites born in 1948. Men born in 1953 were less likely to serve, though many still did (14 percent of whites and 18 percent of nonwhites).

\subsection{The Draft-Lottery First Stage}

The first draft lottery, held in December 1969, affected men born in 1944-50 who were at risk of conscription in 1970, while subsequent draft lotteries affected 19-year-olds only. Men born in 1951 were at risk of conscription in 1971 and men born in 1952 were at risk of conscription in 1972. Men born in 1953 were assigned lottery numbers in 1972, but there were no draft calls in 1973. Although men as old as 26 could have been drafted as a result of the 1970 lottery, the risk of conscription for all cohorts affected by a lottery was limited to a single year.

Each lottery was associated with a draft-eligibility ceiling or cut-off. Those with an RSN below the ceiling were draft-eligible while those with an RSN above the ceiling were draft-exempt. Draft-eligibility ceilings were 195 in the 1970 lottery, 125 in the 1971 lottery and 95 in the 1972 lottery. Draft eligibility is highly correlated with Vietnam-era veteran status, but the link is far from deterministic. Many men with draft lottery numbers below the ceiling were able to avoid conscription (through an occupational or educational deferment, or because of poor health or low test scores) while many with lottery numbers above the ceiling volunteered for service. Throughout the Vietnam era (1964-1975), most

\footnotetext{
${ }^{9}$ The Census question regarding non-SSA retirement and disability income states "Do not include Social Security," while military pensions are presumably included. The "other income" question explicitly mentions "VA payments," which presumably includes VDC. In practice, veterans may confuse VDC and MDP payments though they could not receive both before 2003. Another difference is that VDC is not taxable while disability pensions are.
} 
soldiers were volunteers.

In the sample of men born 1950-52, the effect of draft eligibility on Vietnam-era veteran status is .145 for whites and .094 for nonwhites. These and other draft-eligibility effects are reported in the first rows of Table 2 (Panel A for whites and Panel B for nonwhites). The table also shows draft-eligibility effects for the pooled sample of men born 1948-52. These effects are somewhat smaller than in the younger subsample (.11 for whites and .072 for nonwhites) because the draft-eligibility first-stage is smaller for men born in 1948 and 1949 than for men born in 1950. This is not surprising since many of those who served in the older cohorts had entered the military before the 1970 draft lottery. Table 2 also documents a small draft-eligibility first stage for the 1953 cohort (about .031), where draft-eligibility status was coded using the 1972 lottery cutoff of 95. Because the effect on men born in 1953 is small, we omit this cohort from the empirical analysis that follows. Draft-eligibility effects for men born 1944-47 (not reported here) are smaller than those for men born 1953 so we omit these cohorts as well.

The most important feature of the relationship between lottery numbers and military service is the drop in the probability of service at the draft-eligibility cutoff. This can be seen in Figure 1, which plots nonparametric estimates of the conditional probability of service given lottery numbers for men born 1950-53. The figure shows estimates smoothed across 5-RSN cells by single year of birth, but the smoothing does not straddle the drafteligibility cutoff in each cohort. ${ }^{10}$ The figure also documents modest variation in the probability of service within draft-eligibility groups. Part of this variation is due to higher voluntary enlistment rates among men with low lottery numbers - men who volunteered could expect more choice regarding terms of service (e.g., choice of branch of service), while draftees mostly served in the Army. Another important feature of Figure 1 is the muted relationship between veteran status and lottery numbers for nonwhites. Angrist (1991) shows that this can be explained by the fact that nonwhites were more likely than whites to consider military service an attractive career option.

\subsubsection{Additional Instrument Sets}

In addition to just-identified estimates using a dummy for draft-eligibility status as the single instrument, we also constructed instruments from a set of five lottery-group dummies. These were chosen to match draft-eligibility cutoffs for each cohort, with allowance

\footnotetext{
${ }^{10}$ Estimates were smoothed using lowess with a bandwidth of .4 and a standard tricube weighting function.
} 
for additional draft-motivated enlistment as high as RSN 230. The 5z instrument set for individual $i$ is $\left\{z_{1 i}, z_{2 i}, z_{3 i}, z_{4 i}, z_{5 i}\right\}$ where

$$
\begin{aligned}
z_{1 i} & =I\left[R S N_{i} \leq 95\right] \\
z_{2 i} & =I\left[95<R S N_{i} \leq 125\right] \\
z_{3 i} & =I\left[125<R S N_{i} \leq 160\right] \\
z_{4 i} & =I\left[160<R S N_{i} \leq 195\right] \\
z_{5 i} & =I\left[195<R S N_{i} \leq 230\right]
\end{aligned}
$$

and $I[\cdot]$ is the indicator function. This allows for kinks at each draft-eligibility cutoff, while breaking the set of lottery numbers up into roughly equal-sized groups between RSN 95, the lowest cut-off, and RSN 230, beyond which the effect of lottery numbers on enlistment is negligible. Note that a draft-eligibility dummy $\left(\right.$ elig $\left._{i}\right)$ can be constructed from the elements of $5 z$ as follows

$$
e l i g_{i}=z_{1 i}+I\left[Y O B_{i} \leq 51\right]\left(z_{2 i}\right)+I\left[Y O B_{i} \leq 50\right]\left(z_{3 i}+z_{4 i}\right)
$$

where $Y O B_{i}$ is $i$ 's year of birth. This shows that $e l i g_{i}$ is a function of both lottery-number main effects and interactions with year of birth.

The first two columns in each panel of Table 2 report estimates of the $5 z$ first stage in pooled samples. ${ }^{11}$ These estimates are from models without year-of-birth interaction terms. For example, column 1 shows that men born 1950-52 with RSNs up to 95 were .16 more likely to serve than men with RSNs above 230 (the reference group). The next group, with RSN 96-125, was .091 more likely to serve than the reference group; the next group was .059 more likely to serve; the next group after that was .04 more likely to serve; and the last group with RSN 196-230 was .0065 more likely to serve. All of these first-stage effects are precisely estimated and significantly different from zero. As with the draft-eligibility effects, estimates of $5 z$ effects are consistently smaller for nonwhites than for whites. F-statistics in the pooled 1950-52 and 1948-52 samples range from 134 for nonwhites to over 2400 for whites.

The $5 z$ instrument set without year of birth interactions does not produce more precise 2SLS estimates than $\mathrm{elig}_{i}$ alone. We therefore report estimates using an instrument set, labeled $5 z x$, that interacts $5 z$ with year of birth. The $5 z x$ set includes 15 instruments

\footnotetext{
${ }^{11}$ The estimates in Table 2 and the second-stage estimates that follow control for year of birth, State of birth, and month of birth.
} 
for the 1950-52 sample and 25 instruments for the 1948-52 sample. The $5 z x$ first stage appears in columns 3-7 of Table 2. This first stage documents a modest role for draftmotivated enlistment. For example, even though the 1971 draft-eligibility cutoff was 125, men born in 1951 with lottery numbers between 126 and 160 were .05 more likely to serve than men with lottery numbers above 230 .

Finally, when estimating the returns to schooling, we tried an instrument set (called $7 z x$ ) that adds two RSN dummies plus year-of-birth interactions to $5 z x$. The additional instruments are dummies for RSN 1-30 and RSN 31-60. Most of our substantive conclusions, however, are based on just-identified models or models estimated with a low degree of over identification. ${ }^{12}$

\subsection{Sample Selection Issues}

A final issue before turning to the second-stage estimates is the possibility of selection bias due to excess mortality among draft-eligible men. There are two likely channels for this. The first is war-related deaths, since civilian samples are limited to those who survived the war. The second is elevated post-service mortality due to physical injury, PTSD, or other long-term consequences of military service such as an increased likelihood of cigarette smoking (as suggested by Bedard and Deschenes, 2006, for WWII veterans).

Roughly 47,000 men died as a result of hostile action in the Vietnam Era (1964-75) while 8.7 million personnel served in the military during this period. Overall casualty rates among Vietnam-era veterans were low in part because less than half of active duty personnel served in Indochina, and many served in positions not exposed to combat. Although causality rates among draftees were higher than the overall death rate (because most draftees served in the Army), draftees accounted for a minority of combat deaths. Moreover, over 80 percent of combat deaths occurred before $1970 .{ }^{13}$ It therefore seems unlikely that war-related deaths have a large effect on the composition of the sample used in our study.

An increase in civilian mortality for veterans seems more likely than combat deaths

\footnotetext{
${ }^{12}$ As it turns out, $7 z x$ adds little to the precision obtained with $5 z x$, so we use the larger instrument set only for the Mincer equation. Likewise, a non-parametric first stage using the fitted values from Figure 1 fails to generate a meaningful gain in precision relative to $5 z x$.

${ }^{13}$ Service and casualty statistics are from Table 583 in the 2000 Statistical Abstract, available on-line at http://www.census.gov/prod/2001pubs/statab/sec11.pdf. Data on casualties by year are available from the national archives: http://www.archives.gov/research/vietnam-war/casualty-statistics.html\#year. Statistics on service in Indochina and exposure to combat are from Hearst, Newman and Hulley (1986).
} 
to affect the composition of post-Vietnam samples, especially in view of Hearst, Newman and Hulley's (1986) findings of elevated civilian mortality for draft-eligible men. The excess deaths in the Hearst, Newman and Hulley study are due to suicide and motor vehicle accidents, possibly related to PTSD.

As a simple check on the possibility of mortality-related selection bias, we compared the actual and expected number of draft-eligible men in the 2000 Census by race and year of birth. Following Hearst, Newman, and Hulley (1986), the expected ratio is computed assuming birthdays (and hence lottery numbers) are uniformly distributed. Overall, drafteligible men are represented in the census sample almost exactly as predicted assuming a uniform distribution of lottery numbers. Among whites, the predicted proportion eligible is .40553, while the empirical proportion eligible is .40539. Among nonwhites, the proportion eligible is more than predicted, .4085 versus .4038 .

Comparisons by single year of birth for white men born 1948-53, reported in detail in Appendix Table A3, show draft-eligible men slightly over-represented in three cohorts and slightly under-represented in 3 cohorts (one of these is the 1953 cohort, with no draftees). Some of these differences are significant, though all are small. Only one out of six cohortspecific contrasts is significant for nonwhites, with slightly more eligibles than predicted for nonwhites born in 1950. Given the size and sign pattern of these comparisons, it seems unlikely that excess civilian mortality has a substantial effect on the composition of the 2000 Census sample. This analysis also weighs against the view that Vietnam-era service led to elevated civilian mortality. We return to this point in Section 5.

\section{Labor-Market Effects}

We look first at employment and earnings. The results reported here are 2SLS estimates of the parameter $\alpha$ in the equation

$$
Y_{i}=w_{i}^{\prime} \beta+\alpha v_{i}+\varepsilon_{i},
$$

where $Y_{i}$ is an outcome variable; $v_{i}$ is veteran status; and $w_{i}$ is a vector of covariates that includes year of birth dummies, state of birth dummies, and month of birth dummies. Year of birth is a necessary control in models identified by the exclusion of draft-eligibility since older men were more likely to be eligible. Month of birth adjusts for any bias arising from the fact that the 1970 lottery, the only one to use physical randomization, resulted in an RSN sequence correlated with month of birth (in practice this does not appear to 
be important). State of birth is a natural pre-treatment control, inclusion of which might increase the precision of second-stage estimates. As a benchmark, ordinary least squares (OLS) estimates of equation (1) are also reported.

As discussed in Angrist (1990), 2SLS estimates of equations like (1) capture the effect of service on those who were drafted or who volunteered in the face of draft risk. These men are draft-lottery compliers in the sense of Angrist, Imbens, and Rubin (1996): they served in the Vietnam era because they were assigned a low lottery number but would not have served otherwise. The average causal effect for compliers is the local average treatment effect (LATE) captured by draft-lottery instruments (Imbens and Angrist, 1994).

Most soldiers from the Vietnam period were not compliers; rather, they were true volunteers because they were not drafted and because they did not volunteer to avoid conscription. ${ }^{14}$ Estimates using draft-lottery instruments need not generalize to the population of true volunteers. Nevertheless, the effects of military service on those compelled to serve against their will reflect the historical consequences of conscription. These estimates are also relevant for contemporary discussions of military manpower policy since compliers in the future are likely to be similar to those from the draft-lottery period. ${ }^{15}$ Moreover, given an economic mechanism that explains the effects of Vietnam-era service (such as lost experience), we might draw broader conclusions as to how conscription affects soldiers, though these conclusions require stronger assumptions than an analysis of the causal effect of Vietnam-era conscription per se.

Draft-lottery estimates constructed using the 2000 Census show little evidence of an effect of Vietnam-era conscription on the labor market outcomes of whites. This can be seen in Panel A of Table 3, which reports estimates of effects on labor market status and earnings using different instrument sets. For example, 2SLS estimation using drafteligibility status as an instrument in the sample of white men born 1950-52 generates

\footnotetext{
${ }^{14}$ The proportion of veterans who were compliers can be calculated as follows: let $v_{1 i}$ denote $i$ 's veteran status if $i$ is draft eligible $\left(e l i g_{i}=1\right)$ and $v_{0 i}$ denote $i$ 's veteran status if $i$ is ineligible $\left(\right.$ elig $\left.g_{i}=0\right)$. Random assignment makes elig $g_{i}$ independent of $\left\{v_{1 i}, v_{0 i}\right\}$. Veteran status is $v_{i}=v_{0 i}+e l i g_{i}\left(v_{1 i}-v_{0 i}\right)$ and compliers have $v_{1 i}-v_{0 i}=1$. Given monotonicity, $v_{1 i} \geq v_{0 i}$, so the proportion of draft-eligibility compliers is given by the draft-eligibility first stage, $P\left[v_{1 i}-v_{0 i}=1\right]=E\left[v_{1 i}-v_{0 i}\right]=E\left[v_{i} \mid e l i g_{i}=1\right]-E\left[v_{i} \mid\right.$ elig $\left._{i}=0\right]$. The proportion of veterans who are draft-eligibility compliers is $P\left[v_{1 i}-v_{0 i} \mid v_{i}=1\right]=P\left[v_{i}=1 \mid v_{1 i}-v_{0 i}=\right.$ 1] $P\left[v_{1 i}-v_{0 i}=1\right] / P\left[v_{i}=1\right]=P\left[e \operatorname{elig}_{i}=1\right] P\left[v_{1 i}-v_{0 i}=1\right] / P\left[v_{i}=1\right]$. For white men born 1950-52, this is $.376(.145 / .236)=.231$.

${ }^{15}$ The Selective Service System web site indicates that "if a draft were held today," it would involve a lottery over 19-year olds. There would be few deferments, as in the Vietnam-era lottery, with at most a one-semester deferment for enrolled students. And it seems likely that any future draft would come in wartime. Finally, as in the Vietnam era, those conscripted would be men who do not find GI Bill education benefits enough of an inducement to volunteer. See http://www.sss.gov/viet.htm.
} 
effects of -.0043 (s.e.=.0072) on employment and -517 (s.e.=1240) on earnings. The corresponding estimates in the sample of white men born 1948-52 are -.0047 (s.e.=.0072) and -115 (s.e.=1243). Estimates of effects on log weekly wages, computed for the sample of men with positive earnings, are similarly small. In contrast, the OLS estimates in columns 2 and 6 show that veteran status is associated with substantially worse labor market outcomes and lower employment rates. The OLS estimates, about -7,900 to -8,600 for annual earnings and -11 percent to -12 percent of weekly wages, are outside the 2SLS confidence intervals.

The pattern of OLS estimates is reversed for nonwhites, with veterans more likely to be working and earning more than non-veterans. But the 2SLS estimates in Panel B of Table 3 offer no evidence of a causal effect on the employment or earnings of nonwhites - the estimated earnings effects for nonwhites are positive but insignificant. It should be noted, however, that the 2SLS estimates for nonwhites are considerably less precise than those for whites due both to a smaller sample and a weaker first-stage. Using draft eligibility as an instrument, the estimated effect of Vietnam-era service on the log weekly wages of nonwhites born 1950-52 is -.037 with a standard error of .067. Some of the estimated effects on weeks and hours worked by nonwhites are positive and significantly different from zero, e.g., an increase of 3.7 hours per week in column 7 (s.e.=1.7). There is also some evidence of reduced unemployment for nonwhites in the 1948-52 sample. On the other hand, there is little evidence of a corresponding increase in employment while the estimated effects on weeks worked by nonwhites are positive but insignificant. On balance, therefore, the results for nonwhites seem inconclusive, though perhaps leaning towards positive long-run effects.

Finally, it's noteworthy that the $5 z x$ instrument set incorporating 5 lottery-number dummies with a full set of year-of-birth interactions produces only slightly more precise estimates than elig $_{i}$ alone. The most noticeable precision gains appear in the 1948-52 sample. For example, the standard error for the effect on earnings in the sample of whites born 1948-52 falls from 1243 to 1133, with similar coefficient estimates. The standard error for the effect on log wages changes by only .01 in this sample, from .16 to .15 . 


\subsection{Experience and Earnings}

The 2SLS estimates in Table 3 contrast with the earnings losses reported for white veterans in Angrist (1990), which range from 10-15 percent of FICA-taxable earnings in 1981-84. The results from the 2000 Census can be reconciled with these earlier results if the costs of conscription are due primarily by lost labor market experience. By 2000, the draft lottery cohorts had reached middle age, when experience profiles are fairly flat, so the veteran penalty should have faded. The empirical support for this argument comes from a Mincer-style wage equation, which can be written as

$$
y_{i}=\beta_{0}+\beta_{1} x_{i}+\beta_{2} x_{i}^{2}+\rho s_{i}+u_{i},
$$

where $y_{i}$ is the log weekly wage, $s_{i}$ is years of schooling, $x_{i}$ is potential work experience, and $u_{i}$ is a random component in the human capital earnings function. Potential work experience is assumed to vary with veteran status, $v_{i}$, according to

$$
x_{i}=a g e_{i}-s_{i}-6-v_{i} \ell=\bar{x}_{i}-v_{i} \ell,
$$

where $\bar{x}_{i}$ is potential experience for non-veterans. In other words, veterans have $\ell$ fewer years of experience than non-veterans of the same age and with the same educational attainment.

Equations (2) and (3) lead to a model with an additive veteran effect and an interaction term between $v_{i}$ and $\bar{x}_{i}$. Re-arranging, we have

$$
y_{i}=\beta_{0}+\beta_{1} \bar{x}_{i}+\beta_{2} \bar{x}_{i}^{2}+\rho s_{i}+\pi_{x i} v_{i}+u_{i},
$$

where $\pi_{x i}=\pi_{1}+\pi_{2} \bar{x}_{i}$ and

$$
\begin{aligned}
& \pi_{1}=-\left[\beta_{1} \ell-\beta_{2} \ell^{2}\right] \\
& \pi_{2}=-2 \beta_{2} \ell .
\end{aligned}
$$

Fitting this model to log earnings from 1978-1984, Angrist (1990) estimated $\ell=2.08$ (s.e.=.38), with an experience profile such that $\pi_{1}=-.225$, and $\pi_{2}=.011$. In other words, veterans start out at a -.225 wage disadvantage, but the gap closes by .011 each year. The veteran earnings gap is zero when $\bar{x}_{i} \approx 20.5$ or $a g e_{i} \approx 39$ for high school graduates (older for those with more education).

The pure loss-of-experience model generates a restriction linking $\pi_{1}$ and $\pi_{2}$. An unrestricted model allows the linear potential experience term to vary with veteran status 
according to $\beta_{1 i}=\beta_{10}+\beta_{11} v_{i}$, where $\beta_{11}$ is most likely negative. This can be rationalized by the Ben-Porath (1967) model of human capital investment with a finite horizon, since military service shortens the period of return on investment. The relationship between equation (4) and the human capital earnings function then becomes

$$
\begin{aligned}
& \pi_{1}=-\left[\left(\beta_{10}+\beta_{11}\right) \ell-\beta_{2} \ell^{2}\right] \\
& \pi_{2}=-\left[2 \beta_{2} \ell-\beta_{11}\right] .
\end{aligned}
$$

Since $\beta_{11}$ is an additional free parameter, equations (6a) and (6b) impose no restrictions on (4). The unrestricted estimates are $\ell=1.84$ (s.e. $=.43$ ), $\pi_{1}=-.189$, and $\pi_{2}=.006$. In this case, the veteran earnings gap disappears when $\bar{x}_{i}=.189 / .006=31.5$ or age $i \approx 50$ for those with a high school diploma.

A key implication of both the restricted and unrestricted loss-of-experience models is that by the time of the 2000 Census, the veteran earnings gap should have largely closed and perhaps even reversed. This is illustrated in Figure 2, which plots the profiles estimated from equation (4) assuming veteran status operates to reduce experience as in (3). The upper panel of the figure, based on the unrestricted model allowing veterans to have a profile with lower slope, shows veteran and non-veteran profiles converging by about 2000, while the restricted model has veterans converging sooner. In both cases, however, the broad picture is of a shrinking veteran wage penalty. ${ }^{16}$ A second force that appears to have contributed to the closing veteran wage gap is schooling, discussed in the next section.

\section{Effects on Schooling}

Compulsory military service appears to have increased the educational attainment of Vietnam-era veterans, a result documented in Table 4a. For example, the 2SLS estimates using $\mathrm{elig}_{i}$ in the 1950-52 sample suggest that white veterans got .33 more years of schooling than nonveterans. The corresponding results are slightly lower in the 1948-52 sample, but change little when estimated with an expanded instrument list. Both samples generate precise estimates, with standard errors on the order of .05. In contrast with the results for whites, however, the estimates for nonwhites are smaller, mostly below .2, and not significantly different from zero.

\footnotetext{
${ }^{16}$ Imbens and van der Klaauw (1995) report an estimated earnings loss of about 5 percent for Dutch conscripts ten years after their service. This is consistent with the earnings penalty that might be expected from lost experience given the short period of service in Holland.
} 
The remainder of Table 4a shows that the increase in highest grade completed for white veterans is primarily the result of more years of college, with precisely estimated effects ranging from .24-.27. More specifically, veterans were more likely to attend college (including partial years) or to earn an associate's degree. These effects are on the order of .06-.08. The increase in the likelihood of completing a BA degree is smaller though still marked, at around .05. Perhaps surprisingly, there is also a small effect on high school completion (roughly 2 percentage points) and a very small effect on upper secondary grade completion. These effects may be due to GEDs obtained by veterans without a high school diploma. In addition, since the 1990s, many states have offered Vietnam-era veterans honorary high school diplomas solely on the basis of their military service. ${ }^{17}$

The 2SLS estimates are summarized in Figure 3, which plots the coefficient estimates for the 1948-52 sample reported in Table 4a (as well as some not reported in the table), along with pointwise confidence bands. There is a clear jump in the effects on post-high school schooling levels, with a drop at the BA level. The figure also highlights the much smaller and mostly insignificant shift in the schooling distribution for nonwhite veterans. The single (marginally) significant effect on nonwhites' education is for the likelihood of obtaining some college (but less than a full year). Finally, unlike the 2SLS estimates, OLS estimates with controls for state, month, and year of birth (reported in columns 2 and 6) show white veterans with fewer years of schooling and less post-secondary education. In view of the 2SLS estimates, this would seem to be an artifact of selection bias.

\subsection{GI Bill Benefits vs. Draft Deferments}

The schooling shifts documented in Table $4 \mathrm{a}$ and Figure 3 are most likely a consequence of the Vietnam-era GI Bill, which offered stipends similar in generosity to those available to veterans of WWII and Korea. ${ }^{18}$ Vietnam veterans were especially likely to have used the GI Bill for education and training. Data from the 2001 Survey of Veterans (SOV) show

\footnotetext{
${ }^{17}$ Angrist and Krueger (1992) look at the relation between lottery numbers and education using data from the 1979-85 CPS's. These results are too imprecise to detect effects on schooling of the size reported here. Moreover, some of the veteran schooling advantage seems likely to have accumulated after Angrist and Krueger's (1992) sample period.

${ }^{18}$ The WWII GI Bill included a 500 tuition benefit and a monthly stipend. In the 1970s, the Vietnamera GI Bill paid full-time students a stipend almost identical in value to the WWII package (adjusting for inflation) and more generous than the Korean-era full-time stipend. These benefit levels were almost double the average cost of tuition, room, and board at 4-year public universities in this period. The real value of the Vietnam-era GI Bill declined in the 1980s, but remained above the cost of tuition, room, and board (Data from authors' tabulations and Bound and Turner, 2002).
} 
that among whites, 44 and 42 percent of WWII and Korean-era veterans used benefits for education and training, while the usage rate was 50 percent for Vietnam-era veterans. Vietnam-era veterans were also more likely than earlier cohorts to have used their benefits for college course work: 63 percent of Vietnam-era GI Bill beneficiaries used benefits for college courses, while the corresponding figures for WWII and Korean-era benefit users are 53 and 56 percent. ${ }^{19}$

The notion that the GI Bill increased schooling is supported by a number of earlier studies. For example, Bound and Turner's (2002) preferred IV estimates of the effects of WWII service on college completion by white men are around 5-6 percentage points while their preferred estimates of effects on years of college range from .23-.28. Stanley's (2003) estimates of the effects of the Korean-era GI Bill eligibility on college completion are also on the order of 5-6 percentage points while his estimates of effects on years of college range from .20-.33. The college completion effects reported in Table 4a are a little over 5 points for whites and range from .24-.27 for years of college, remarkably similar to the Bound and Turner (2002) and Stanley estimates. The estimates in Table 4a also echo Turner and Bound (2003) in that they show larger effects of the GI Bill on whites than nonwhites. Finally, Lemieux and Card (2001) report effects of a similar magnitude in cohorts that benefitted from the Canadian GI Bill, while Angrist (1993) finds large post-service schooling increases associated with the use of the Vietnam-era GI Bill. ${ }^{20}$

The leading alternative explanation for schooling effects estimated using draft-lottery instruments is draft-avoidance behavior through education-related draft deferments. In the 1960s, college students could delay and eventually escape conscription by staying in school. Men with low draft lottery numbers may therefore have been more likely to stay in college or to enroll in college, hoping to avoid service through an educational deferment. Weighing against this possibility is the fact that the importance of educational deferments

\footnotetext{
${ }^{19}$ The pattern for nonwhite veterans is similar, though the levels are lower. GI Bill statistics in this paragraph are from the authors' tabulation of responses to the 2001 SOV. For purposes of this comparison, samples of veterans were limited to the principle birth cohorts who served in each era (years of birth with at least 100 observations in the SOV).

${ }^{20}$ The BEOG program (Pell grants) also played an important role in expanding college attendance for adult students in the 1970s (see, e.g., Seftor and Turner 2002), but Vietnam veterans were not especially likely to have received Pell grants. Among male Vietnam veterans aged 35-39 in the SOV of 1987 (roughly the cohorts of the 2000 Census), 54 percent had used the GI Bill, while only 7.4 percent reported having received any federal (non-Veteran) aid, and only 2.3 percent received federal grants (including Pell grants). The overlap with Pell grants is small because Pell was means-tested while the GI Bill was not and because half of the GI Bill benefit amount was counted as income when determining Pell grant eligibility (U.S. Congressional Budget Office 1978, p.24).
} 
declined sharply during the draft-lottery period. ${ }^{21}$

\subsection{Additional Evidence on the GI Bill Hypothesis}

Estimates of schooling effects by single year of birth, reported in Table 4b, also weigh against draft deferment as the primary force behind the schooling effects in Table 4a. In particular, Table 4b shows that in spite of the decreasing availability of college deferments from 1970 onwards, the estimated effects on highest grade completed and years of college are substantial for white men born in 1951 and 1952. The largest effects of military service on these two schooling variables are for the 1951 cohort, few of whom would have been deferred for long. Estimates of effects on highest grade completed and years of college for the 1952 cohort (which had no access to college deferments) are smaller, but similar in magnitude or larger than the estimated effects on white men born from 1948-50.

Differences across cohorts in the 2SLS estimates of effects on some-college dummies mirror the differences in estimates of effects on highest grade completed and years of college. For example, the estimated effect on a dummy variable indicating one or more years of college falls from .105 for the 1951 cohort to .068 for the 1952 cohort. On the other hand, the BA effect is larger for the 1952 cohort than for the 1950 cohort, in spite of the latter's wider access to college deferments. It's also worth noting that the estimates by single year of birth for nonwhites, though imprecise, are typically larger for younger cohorts than old. On balance, therefore, Table 4b points away from draft deferment as the primary explanation for the results in Table $4 \mathrm{a}$.

\section{Schooling Trends in the CPS}

A second piece of evidence supporting the GI Bill explanation of increased schooling among Vietnam veterans comes from the Current Population Surveys (CPS). This evidence is based on a model that divides total educational attainment into three parts: pre-service schooling for veterans or schooling completed as of the typical entry age for non-veterans $\left(s_{i}^{A}\right)$; schooling acquired between the typical entry and discharge ages $\left(\Delta s_{i}^{B}\right)$; and the difference between completed schooling and the schooling completed at the typical

\footnotetext{
${ }^{21}$ The decline in the role played by college deferments is reflected in the cohort- and sex- specific enrollment rates analyzed by Card and Lemieux (2001). Their analysis shows no deviation from trend in the male-to-female college graduate ratio or the proportion with some college in cohorts born 1950 or later. For institutional background related to draft deferments, see the chronology in Selective Service System Office of Public Affairs (1986) and Semiannual Reports of the Director of the Selective Service System from the early 1970s.
} 
discharge age $\left(\Delta s_{i}^{C}\right)$. Completed education is the sum of these components:

$$
s_{i}=s_{i}^{A}+\Delta s_{i}^{B}+\Delta s_{i}^{C},
$$

We think of $s_{i}^{A}$ as schooling at age $20, s_{i}^{A}+\Delta s_{i}^{B}$ as schooling at age 24 , and $s_{i}$ as schooling at around age 40 when GI Bill eligibility expired for the cohorts studied here.

Military service has a causal effect on $\Delta s_{i}^{B}$ and $\Delta s_{i}^{C}$, while $s_{i}^{A}$ is a "pre-treatment" variable. To make this explicit, let $\Delta s_{i}^{B}(v)$ denote the potential schooling acquired during the service period, where $v=0,1$ indexes veteran status. Similarly, let $\Delta s_{i}^{C}(v)$ denote the potential schooling acquired in the post-service period. Veteran and non-veteran potential schooling increments are defined for all $i$ regardless of veteran status.

Most soldiers get no schooling in the military $\left(\Delta s_{i}^{B}(1)=0\right)$, so that

$$
\Delta s_{i}^{B}=\Delta s_{i}^{B}(0)\left(1-v_{i}\right)
$$

We also assume that non-veterans complete their education by the time most veterans are discharged, so that $\Delta s_{i}^{C}(0)=0$. Therefore,

$$
\Delta s_{i}^{C}=\Delta s_{i}^{C}(1) v_{i}
$$

Combining these two assumptions with the decomposition in (7), the causal effect of veteran status on an individual veteran's schooling is $\left[\Delta s_{i}^{C}(1)-\Delta s_{i}^{B}(0)\right]$. The average causal effect of military service on veterans' schooling is

$$
E\left[\Delta s_{i}^{C}(1)-\Delta s_{i}^{B}(0) \mid v_{i}=1\right]=E\left[\Delta s_{i}^{C}(1) \mid v_{i}=1\right]-E\left[\Delta s_{i}^{B}(0) \mid v_{i}=1\right] .
$$

Military service increases average education when post-discharge increases in schooling are enough to overcome the education lost while serving.

We measure $E\left[\Delta s_{i}^{C}(1)-\Delta s_{i}^{B}(0) \mid v_{i}=1\right]$ directly using CPS data from 1964-1991. This covers the period from the beginning of the Vietnam era to just beyond the expiration of Vietnam-era GI Bill entitlements in 1989. Under the assumptions given here, the veteran/nonveteran difference in schooling growth from entry age to completion is

$$
E\left[s_{i}-s_{i}^{A} \mid v_{i}=1\right]-E\left[s_{i}-s_{i}^{A} \mid v_{i}=0\right]=E\left[\Delta s_{i}^{C}(1) \mid v_{i}=1\right]-E\left[\Delta s_{i}^{B}(0) \mid v_{i}=0\right] .
$$

Assuming $E\left[\Delta s_{i}^{B}(0) \mid v_{i}=0\right]=E\left[\Delta s_{i}^{B}(0) \mid v_{i}=1\right]$, that is, the schooling veterans would have obtained during their service years had they not served is equal to the schooling 
non-veterans obtained at the same ages, equation (9) is the average causal effect of veteran status on schooling expressed in equation (8). However, the schooling non-veterans obtained during the service period, $E\left[\Delta s_{i}^{B}(0) \mid v_{i}=0\right]$, probably exceeded the schooling veterans lost while in the military, $E\left[\Delta s_{i}^{B}(0) \mid v_{i}=1\right]$. Thus, the empirical counterpart of (9) is an underestimate of (8).

In line with this reasoning, CPS data show that the educational attainment of Vietnam veterans born 1948-52 increased relatively little when these men were in their early twenties, while the schooling of non-veterans the same age was rising sharply. On the other hand, while the age-schooling profile of non-veterans flattened relatively early, the schooling of Vietnam veterans continued to increase when these men were in their thirties. This can be seen in Figure 4, which plots educational attainment by age and veteran status. A drawback of the CPS for our purposes is that most active duty soldiers are not in the sampling frame so we miss many veterans. The figure therefore shows two panels, constructed with and without those active duty soldiers who are included in the CPS (this includes soldiers stationed in the US, living off-base or with their families). The schooling profiles in both versions exhibit a similar pattern. ${ }^{22}$

As a comparison, Figure 4 also shows schooling profiles for veterans and non-veterans from Korean-war cohorts. These are similar to the Vietnam-era profiles at the same ages. Interestingly, however, while Vietnam veterans had less schooling than Korea veterans around the time Vietnam veterans were discharged, by the end of the period covered in the figure, Vietnam veterans were more educated than Korean-era veterans and had largely closed the gap with non-veterans their same age.

The empirical counterpart of equation (9) appears in Figure 5. Panel A plots the difference in average education by veteran status at each age. The differences for single years of age were smoothed using either a two-year or three-year moving average. The figure highlights the rapidly increasing and then shrinking veteran/non-veteran schooling differential. ${ }^{23}$

Panel B plots the veteran/nonveteran difference in the moving average of schooling, relative to the average over the first two or three years of age in Panel A. We think of this

\footnotetext{
${ }^{22} \mathrm{~A}$ detailed description of the data and methods used to construct Figures 4 and 5 appears in the appendix.

${ }^{23}$ The sample used here includes active-duty CPS respondents. The absence of most active-duty soldiers probably tends to bias the average schooling for veterans upwards at young ages since some of those counted as veterans may have returned to school while active-duty soldiers have not yet had the chance to do so.
} 
as the veteran/nonveteran difference in schooling growth, i.e., after subtracting the average of $s_{i}^{A}$ for each group This plot shows that relative to each group's entry-period schooling level, veterans' schooling grew more than nonveterans'. The corresponding difference-indifferences estimates using (9) are on the order of .1-.3 years of schooling depending on the moving average window and the width of the age range in the terminal group. Thus, our analysis of CPS data on schooling trends comes down remarkably close to the 2SLS estimates of the effect of veteran status on schooling using draft lottery instruments. These estimates can be explained by Vietnam veterans' relatively large increase in educational attainment after their service.

\section{Other outcomes}

Changes in health provide an additional channel whereby military service may have affected earnings. Health effects are especially a concern in view of Hearst, Newman and Hulley's (1986) pioneering draft-lottery study, which found elevated civilian mortality risk among draft-eligible men. As noted in Section 2, however, we found no evidence that draft-eligible men are disproportionately missing in the 2000 Census, as might be expected if Vietnam veterans suffered excess mortality. A number of recent studies using the draft lottery also report less evidence of adverse health consequences than appear in Hearst, Newman, and Hulley (1986). ${ }^{24}$

The mixed evidence for health consequence of Vietnam-era service notwithstanding, the possibility that military service affected health is a clear concern in principle. Veterans may have been injured in combat, either physically or as a result of post-traumatic stress disorder (PTSD). Many Vietnam veterans have also been concerned about exposure to the Agent Orange defoliant used by American forces. Finally, the loss of earnings associated with Vietnam-era conscription may itself have been debilitating. We therefore look directly at disability outcomes in the Census. As detailed in the discussion of Table 1,

\footnotetext{
${ }^{24}$ Goldberg, Richards, Anderson, and Rodin (1991) found no evidence of increased alcohol consumption among draft-eligible men. Dobkin and Shabani (2006), using draft-lottery instruments, conclude that there is no clear evidence for effects of Vietnam-era service on a range of health outcomes. Hearst, Buehler, Newman and Rutherford (1991), using draft-lottery instruments, found no increase in AIDS among Vietnam-era veterans. Bedard and Deschenes (2006) suggest that WWII service increased smoking and smoking-related disease, probably because WWII veterans were given free cigarettes. This was not true in the Vietnam era, however. Eisenberg and Rowe (2007), using draft-lottery instruments, find some evidence of increased smoking in the immediate post-Vietnam period, but the effects are imprecise and disappear in later data. They also find no evidence of effects on other health outcomes.
} 
the Census disability variables include self-reported disability status and disability-related income.

The 2SLS estimates of effects on disability outcomes in Table 5 suggest that Vietnamera conscription increased self-reported disability rates among white veterans. The estimated effects on the likelihood of reporting a non-work disability in the 1948-52 sample, reported in columns 3 and 4 of Table 5, are around .013 for whites. ${ }^{25}$ Both of the 2SLS effects are significantly different from zero, with standard errors on the order of .005. Among individual disability categories, the largest effects are on mobility-related disabilities. On the other hand, the 2SLS estimates show no evidence of an impact on work-related disability rates, as can be seen in the first row of Table 5. There is also little evidence of an effect on disability for nonwhites, with (marginally) significant estimates for one outcome only (vision or hearing).

The 2SLS estimates also suggest that compulsory military service increased the amount of disability-related income received by white veterans. The estimates for whites range from about $\$ 270-300$ for the Other Income variable that includes VDC, with a .04 increase in the likelihood of receipt, to $\$ 480-560$ for the Retirement and Disability income variable that includes MDP, with a .03 increase in the likelihood of receipt. All of these estimates are reasonably precise. The 2SLS estimates of effects on disability-related income variables for nonwhites are roughly double those for whites but considerably less precise and only marginally significant.

The increased receipt of disability-related income reported in Table 5 is partly a mechanical phenomenon since only veterans are eligible for VDC and MDP. On the other hand, the higher disability rates reported in Table 5 may reflect a negative causal impact on health for white veterans. Weighing against this is the absence of an effect of Vietnam-era service on work-related disability, a seeming inconsistency. A second finding inconsistent with an adverse long-term health impact of service is the absence of an effect on employment outcomes: the disability increase reported in Table 5 for whites does not appear to translate into lower employment rates, higher unemployment, or reduced hours and weeks worked, as would usually be expected for disabled workers (see Table 3). Especially striking is the fact that nonwhite veterans have more disability-related income, while also appearing to work more.

Given these inconsistencies, the estimated impact on disability rates for veterans may

\footnotetext{
${ }^{25}$ Estimates for the sample of men born $1950-52$ are similar.
} 
reflect, at least in part, the financial incentives in the veterans' compensation system. As Autor and Duggan (2007) have noted, veterans have a strong incentive to claim benefits because VDC is not taxed to offset earnings (though MDPs are means-tested). Moreover, Duggan, Rosenheck and Singleton (2007) show that enrollment in the VDC program seems highly sensitive to small changes in eligibility criteria and to the unemployment rate. Claims for civilian Social Security Disability Insurance have similarly been linked to labormarket conditions for low-skilled men (Autor and Duggan, 2003). The growth in VDC claims has been large enough to raise questions about the VA's disability determination process. A recent VA study investigates the growth in VDC claims from 1999-2004 and the large variation in these claims across states. ${ }^{26}$

\section{Disability Trends in the CPS}

To get an independent look at trends in veterans health and disability income, we tabulated the amount and proportion receiving income from the VA (including VDC) and the amount and proportion receiving non-Social-Security disability income (including MDP) in the CPS. The results are plotted by year and veteran status for Vietnam and Korea cohorts in Figures 6 and 7. Few nonveterans have income in either the VA or disability categories while both Korea and Vietnam-era veterans have substantial amounts. Importantly, the proportion of Vietnam-era veterans with VA and disability income appears to jump in the late 1990s, a striking change in comparison with the flatter or declining trend for Korea veterans.

Direct measures of self-reported disability rates and the likelihood of fair-to-poor health, plotted in Figure 8, also show a jump for Vietnam veterans around the same time that disability income went up. This might signal a deterioration in the health of Vietnam veterans, but the suddenness of the recent increase in both disability rates and the receipt of disability income suggests that policy or regulatory changes may play a role. It is also worth noting that the causality between self-reported disability and

\footnotetext{
${ }^{26}$ Among other things, the success rates and the amount awarded to VDC claimants appear to be associated with the likelihood that claimants used power-of-attorney representatives from veterans service organizations (VA, 2005). Also related is the fact that diabetes claims for Vietnam veterans jumped sharply after a 2001 VA ruling allowing diabetes to be treated as service-related (based on evidence linking diabetes to Agent Orange; see Autor and Duggan, 2007). This ruling is unlikely to affect disability outcomes in the 2000 Census. On the other hand, PTSD claims by Vietnam veterans grew 18 percent from 1999 to 2001, before the events of September 11 (Veterans Benefits Administration, 2000 and 2002). In 2001, PTSD was the second-largest category of Vietnam-era claims and three-quarters of all PTSD claims were by Vietnam veterans.
} 
disability income can run in both directions; a deterioration in cohort health may have increased claims, but increases in VDC awards may also increase the likelihood that veterans categorize themselves as disabled or as suffering from poor health in government surveys (the disability question in the CPS is a screener for questions about disability income). On balance, therefore, it seems fair to interpret the data on disability outcomes as inconclusive.

\section{Schooling, Experience and Earnings}

Here, we bring the experience and schooling channels together in a Mincer-style wage equation. We are especially interested in the economic return to the extra schooling veterans received as a consequence of the GI Bill. In view of the disability effects reported in the previous section, we also explore models that allow for higher disability rates among Vietnam-era veterans.

The empirical framework in this section is similar to that outlined in equations (2) and (3), with additional exogenous covariates (month of birth and state of birth). Veteran status is assumed to affect wages by reducing potential experience $x_{i}$ and increasing schooling $s_{i}$, but with no direct effects. The loss of experience associated with veteran status is fixed at 2 years, as estimated in Angrist (1990) and consistent with the terms of service for draftees. The equation of interest has three endogenous variables: $x_{i}, x_{i}^{2}$ and $s_{i}$. Age and cohort effects are assumed to be captured by the potential-experience quadratic so that age or year of birth is available as an instrument. ${ }^{27}$

Estimates of equation (2) are reported in Table 6 for the sample of white men born 1948-52. We focus on whites because the estimated impact of military service on the schooling of nonwhites is much smaller. The 1948-52 sample is more useful than the 195052 sample in this context because the wider age range helps to pin down the experience profile. As a benchmark, column (1) reports OLS estimates treating all variables as exogenous. With potential experience defined as in equation (3), the returns to schooling are about .12. The estimated experience profile in this case does not have the usual concavity, reflecting the fact that the profile in this age range is essentially flat (the experience derivative is small, about .009 (s.e.=.0006)). The implicit veteran effect on earnings, constructed from (5a) and (5b), gives the predicted earnings loss due to veterans'

\footnotetext{
${ }^{27}$ This corresponds to the pure loss of experience model. 2SLS estimates of schooling coefficients in a model allowing the linear experience term to vary with veteran status are similar but less precise.
} 
lost experience. This is equal to -.016 (s.e.=.0011). ${ }^{28}$

Instrumental variables estimates of the return to schooling are considerably smaller than the corresponding OLS estimates. This can be seen in columns 2-8 of Table 6 , which report 2SLS and LIML estimates of (2). In over-identified models, LIML provides a check on finite-sample bias in $2 \mathrm{SLS}^{29}$ As shown in column 2, estimates from a justidentified model using $a g e_{i}, a g e_{i}^{2}$ and draft-eligibility $\left(e l i g_{i}\right)$ as instruments for the three endogenous variables $x_{i}, x_{i}^{2}$ and $s_{i}$ generate a return of .07 (s.e.=.035). Swapping year-ofbirth dummies for $a g e_{i}$ and $a g e_{i}^{2}$ generates a 2SLS estimate of .078 (s.e.=.034), reported in column 3 .

The F-statistic for all excluded instruments in column 3 is large (93.3), but this is misleading since age and year of birth serve as instruments for potential experience more than for schooling. The F-statistic for RSN-instruments only (in this case, a single drafteligibility dummy) is 39.4 in column 3 , roughly the square of the t-statistic for the justidentified schooling model in Table 4a. Most relevant is an F-statistic that explicitly takes account of multiple endogenous variables in the 2SLS procedure. This statistic, which adjusts for the fact that all the instruments predict all the endogenous variables, is smaller still (a value of 15 in column 3), but still outside the range where bias in 2SLS estimates is usually a concern. ${ }^{30}$ The LIML estimates in column 4 are close to the corresponding 2SLS estimates, as expected since the degree of over-identification for the

\footnotetext{
${ }^{28}$ Estimates using linear potential-experience controls (i.e., dropping the quadratic term), not reported to save space, are almost identical to those reported in Table 6 (linear experience coefficients are close to the average experience derivatives in the quadratic model).

${ }^{29}$ The finite-sample behavior of LIML is discussed in, e.g., Anderson, Kunitomo, and Sawa (1982).

${ }^{30}$ The multivariate first-stage $\mathrm{F}$ is constructed as follows. Assume covariates have been partialled out of the instrument list and that there are two endogenous variables, $W_{1}$ and $W_{2}$ with coefficients $\delta_{1}$ and $\delta_{2}$. We are interested in the bias of the 2SLS estimator of $\delta_{2}$ when $W_{1}$ is also treated as endogenous. In matrix notation, the instrument vector is $Z$, with projection matrix $P_{z}=Z\left(Z^{\prime} Z\right)^{-1} Z^{\prime}$. The second stage equation is

$$
y=P_{z} W_{1} \delta_{1}+P_{z} W_{2} \delta_{2}+\left[\epsilon+\left(W_{1}-P_{z} W_{1}\right) \delta_{1}+\left(W_{2}-P_{z} W_{2}\right) \delta_{2}\right],
$$

where $\epsilon$ is the vector of structural errors. The 2SLS estimator of $\delta_{2}$ can be seen to be the OLS regression on $P_{z}\left[M_{1 z} W_{2}\right]$, where $M_{1 z}=\left[I-P_{z} W_{1}\left(W_{1}^{\prime} P_{z} W_{1}\right)^{-1} W_{1}^{\prime} P_{z}\right]$. This is also 2SLS using $P_{z}$ to instrument $M_{1 z} W_{2}$. In other words, the endogenous variable of interest is $M_{1 z} W_{2}$, itself the residual from a 2SLS regression of $W_{2}$ on $W_{1}$. Note that the 2SLS estimator of $\delta_{2}$ can be written

$$
\delta_{2}+\left[W_{2}^{\prime} M_{1 z} P_{z} M_{1 z} W_{2}\right]^{-1} W_{2}^{\prime} M_{1 z} P_{z} \epsilon .
$$

The explained sum of squares (numerator of the F-statistic) that determines bias is therefore the expectation of $\left[W_{2}^{\prime} M_{1 z} P_{z} M_{1 z} W_{2}\right]$, as can be shown formally using the group-asymptotic sequence in Bekker (1994) and Angrist and Krueger (1995).
} 
model reported in column 3 is two.

In an attempt to increase the precision of the estimated schooling coefficients, we used the $5 z x$ and $7 z x$ instrument sets constructed from 5 and 7 RSN dummies interacted with year of birth. The resulting 2SLS estimates of the returns to schooling, reported in columns 5 and 7 of Table 6, are indeed more precise than the estimates in columns 2 and 3, though they are also smaller. For example, the estimated returns to schooling using the $5 z x$ and $7 z x$ instrument sets are .043 (s.e.=.03) and .051 (s.e.=.028). The multivariate first-stage F-statistics for both of these models are low, about 3.6 in column 5 and 2.9 in column 7 . This is a consequence of that fact that many of the interaction terms included in the expanded instrument lists have little predictive power. Also of concern in the heavily over-identified specifications is the fact that the LIML estimates fall to zero with standard errors almost twice as large as those for the corresponding 2SLS estimates. Interestingly, the precision of the LIML estimates decreases with the degree of over-identification. Overall, therefore, the low degree-of-overidentification estimates in columns 2 and 3 appear more reliable. ${ }^{31}$

Finally, we estimate a model that allows disability rates to increase with Vietnam-era service:

$$
y_{i}=\beta_{0 \gamma}+\beta_{1 \gamma} x_{i}+\beta_{2 \gamma} x_{i}^{2}+\rho_{\gamma} s_{i}+\gamma d_{i}+u_{i}
$$

where $d_{i}$ indicates non-work disability status (the disability variable that is most affected by veteran status in Panel A of Table 5), with coefficient $\gamma$. The addition of $d_{i}$ to the list of endogenous variables generates highly imprecise results, but we can get a sense of the consequences of higher disability rates for 2SLS estimates of equation (10) by inserting plausible values of $\gamma=\gamma^{*}$ in the following model

$$
y_{i}^{*} \equiv y_{i}-\gamma^{*} d_{i}=\beta_{0 \gamma}+\beta_{1 \gamma} x_{i}+\beta_{2 \gamma} x_{i}^{2}+\rho_{\gamma} s_{i}+\epsilon_{i}
$$

As a benchmark, we set $\gamma^{*}=-.2$, slightly larger in magnitude than the OLS estimate of the wage loss associated with non-work disabilities using equation (10).

Adjusting for disability status in this manner increases the 2SLS estimates of the returns to schooling by .005-.007, as Panel B of Table 6 shows. Variations on these results

\footnotetext{
${ }^{31}$ The standard errors reported for both the LIML and 2SLS estimates in Table 6 are heteroscedasticityconsistent. LIML is motivated by a homoscedastic normal model but can be understood as a k-class estimator in either case. The collapse of LIML in columns 5 and 7 may be explained by the group-asymptotic inconsistency of LIML under some forms of heteroscedasticity. Hausman, Newey, and Woutersen (2006) report a heteroscedastic simulation in a many-weak IV scenario where the bias of LIML is away from OLS.
} 
for alternative choices of $\gamma^{*}$ can be obtained by observing that $\widehat{\rho}_{\gamma}$, the 2SLS estimate of the schooling coefficient in equation (11), is related to $\widehat{\rho}$, the 2SLS estimate of the schooling coefficient imposing $\gamma^{*}=0$, as follows:

$$
\widehat{\rho}_{\gamma}=\widehat{\rho}-\widehat{\lambda} \gamma^{*}
$$

where $\widehat{\lambda}$ is the 2SLS estimate of the coefficient on $s_{i}$ in a regression of $d_{i}$ on the variables on the right-hand side of (11), again, treating all variables as endogenous. Because $\widehat{\lambda}$ in this adjustment is only about .03, the difference between $\widehat{\rho}_{\gamma}$ and $\widehat{\rho}$ is small for any plausible value of $\gamma^{*}$.

A low economic return to GI-Bill-subsidized schooling is not a universal finding. Using the Canadian WWII-era GI Bill as a source of exogenous variation, Lemieux and Card (2001) report IV estimates larger than the corresponding OLS estimates. But attenuated returns to post-service schooling are broadly in line with a number of earlier investigations of the returns to schooling for Vietnam veterans. For example, Schwartz (1986) estimated the returns to schooling to be .025 lower for Vietnam veterans than for comparably-aged non-veterans, while Angrist (1993) reported a return to Vietnam veterans' post-service schooling of .043 using the 1987 survey of veterans. Moreover, as noted by Berger and Hirsch (1983), low returns to GI-Bill schooling can be explained by the large subsidies provided through the Bill. ${ }^{32}$

\section{Summary and Conclusions}

Consistent with a flattening of age-earnings profiles in middle age, the adverse economic consequences of Vietnam-era military service appear to have faded. At the same time, 2000 census data show a strong positive connection between schooling and military service. This schooling gain is very likely due to the Vietnam-era GI Bill. Overall, the schooling effects estimated here are similar to those reported in earlier studies of the WWII and Korean-era GI bills.

Seen through the lens of a Mincer-style wage equation, the near-zero veteran wage penalty can be explained by the combination of lost experience and the economic return to additional schooling. The net effect of GI-Bill funded schooling on earnings in the

\footnotetext{
${ }^{32}$ Heckman, Lochner, and Todd (2005) estimate the impact of tuition and taxes on the internal rate of return to schooling under alternative assumptions. They find that tuition reduces the internal rate of return to college completion for whites in the 1990 Census by about one quarter.
} 
1948-52 sample is on the order of 2.3 percent in the 2000 data - the result of a .294 increase in highest grade completed times a .078 return (estimated using a single drafteligibility instrument). The loss in earnings to veterans due to lost experience amounts to about 1.3 percent. Veterans may also have suffered a small earnings loss due to increased disability rates, though there are no corresponding effects on employment or work-related disabilities.

Finally, it is noteworthy that 2SLS estimates of the returns to post-service schooling are considerably smaller than the corresponding OLS estimates. This is unusual in the literature using instrumental variables to estimate the returns to schooling, but it is consistent with optimal schooling choices based on a comparison of marginal costs and marginal benefits. The low economic returns to GI-Bill funded schooling may reflect the unusually large subsidies for schooling available to veterans. 
Table 1. Basic descriptive statistics, by race and veteran status, for men born 1950-52

\begin{tabular}{|c|c|c|c|c|c|c|}
\hline & \multicolumn{3}{|c|}{ Whites } & \multicolumn{3}{|c|}{ Nonwhites } \\
\hline & $\begin{array}{l}\text { All } \\
(1) \\
\end{array}$ & $\begin{array}{c}\text { Vietnam veteran } \\
(2) \\
\end{array}$ & $\begin{array}{c}\text { Non-veteran } \\
\text { (3) }\end{array}$ & $\begin{array}{l}\text { All } \\
(4) \\
\end{array}$ & $\begin{array}{c}\text { Vietnam veteran } \\
(5) \\
\end{array}$ & $\begin{array}{c}\text { Non-veteran } \\
(6) \\
\end{array}$ \\
\hline Draft eligibility (by RSN) & .376 & .532 & .327 & .382 & .482 & .350 \\
\hline Veteran status (served in Vietnam Era) & .236 & 1 & 0 & .244 & 1 & 0 \\
\hline Post-Vietnam service & .038 & .064 & .030 & .068 & .078 & .065 \\
\hline Now in military & .0027 & .0065 & .0015 & .0029 & .0067 & .0016 \\
\hline Now in school & .028 & .031 & .027 & .046 & .053 & .043 \\
\hline Age & 48.2 & 48.4 & 48.2 & 48.2 & 48.3 & 48.2 \\
\hline \multicolumn{7}{|c|}{ A. Labor market variables } \\
\hline Employment & .861 & .844 & .866 & .665 & .702 & 654 \\
\hline Unemployment & .027 & .030 & .026 & .056 & .053 & .057 \\
\hline Not in labor force & .112 & .126 & .108 & .279 & .245 & .290 \\
\hline Usual hours worked & 41.5 & 40.7 & 41.7 & 32.8 & 34.3 & 32.3 \\
\hline Weeks worked & 44.8 & 44.1 & 45.0 & 35.9 & 37.5 & 35.4 \\
\hline Wage and salary income & 46406 & 39472 & 48553 & 27584 & 28505 & 27287 \\
\hline Log weekly earnings (positive values) & 6.75 & 6.65 & 6.78 & 6.41 & 6.43 & 6.41 \\
\hline Self employment income (positive values) & 5261 & 3123 & 5923 & 1709 & 1230 & 1863 \\
\hline \multicolumn{7}{|c|}{ B. Disability and disability income variables } \\
\hline Work disability & .123 & .136 & .118 & .210 & .207 & .211 \\
\hline Non-work disability & .070 & .084 & .066 & .116 & .120 & .114 \\
\hline Mobility disability & .082 & .103 & .075 & .132 & .145 & .128 \\
\hline Self-care disability & .021 & .023 & .021 & .040 & .036 & .041 \\
\hline Physical disability & .051 & .055 & .050 & .121 & .111 & .124 \\
\hline Mental disability & .044 & .049 & .042 & .073 & .072 & .073 \\
\hline Vision or hearing disability & .036 & .042 & .034 & .045 & .045 & .045 \\
\hline Other income (includes VDC) & 392 & 754 & 279 & 566 & 1085 & 398 \\
\hline Other income $>0$ & .054 & .107 & .037 & .072 & .134 & .052 \\
\hline Retirement and disability pensions (includes MDP) & 691 & 1445 & 458 & 848 & 1622 & 598 \\
\hline Retirement/Dis. income $>0$ & .043 & .091 & .028 & .065 & .118 & .047 \\
\hline \multicolumn{7}{|c|}{ C. Education variables } \\
\hline Imputed highest grade completed & 13.8 & 13.3 & 13.9 & 12.6 & 13.0 & 12.4 \\
\hline Years of college $(0-4)$ & 1.73 & 1.34 & 1.85 & 1.02 & 1.10 & .988 \\
\hline 9th grade + & .977 & .988 & .974 & .948 & .981 & .938 \\
\hline 10th grade + & .965 & .978 & .961 & .923 & .970 & .908 \\
\hline 11th grade + & .948 & .962 & .943 & .882 & .950 & .860 \\
\hline 12th grade (no diploma) + & .931 & .949 & .926 & .832 & .923 & .802 \\
\hline High school graduate + & .910 & .927 & .904 & .770 & .881 & .735 \\
\hline Some college (less than 1 year) + & 655 & 616 & 667 & .468 & .585 & .431 \\
\hline 1 or more years of college (no degree) + & .582 & .519 & 601 & .400 & .486 & .372 \\
\hline Associate's degree + & .411 & .313 & .441 & .226 & .243 & .221 \\
\hline Bachelor's degree + & .333 & .204 & .373 & .160 & .136 & .168 \\
\hline Master's degree + & .135 & .071 & .155 & .057 & .042 & .062 \\
\hline Professional degree + & .051 & .017 & .061 & .018 & .0094 & .021 \\
\hline $\mathrm{N}$ & 696530 & 166652 & 529878 & 96217 & 23246 & 72971 \\
\hline
\end{tabular}

Note: Sampling weights are used in all estimates and statistics. 
Table 2. First-stage, by race and year of birth

\begin{tabular}{|c|c|c|c|c|c|c|c|c|}
\hline & \multicolumn{2}{|c|}{ Pooled cohorts } & \multicolumn{6}{|c|}{ By single year of birth } \\
\hline & $\begin{array}{c}1950-52 \\
\text { (1) }\end{array}$ & $\begin{array}{c}1948-52 \\
(2)\end{array}$ & $\begin{array}{c}1948 \\
(3)\end{array}$ & $\begin{array}{c}1949 \\
(4)\end{array}$ & $\begin{array}{c}1950 \\
(5)\end{array}$ & $\begin{array}{c}1951 \\
(6)\end{array}$ & $\begin{array}{c}1952 \\
(7)\end{array}$ & $\begin{array}{c}1953 \\
(8) \\
\end{array}$ \\
\hline Draft-eligibility effect & $\begin{array}{c}.145 \\
(.0013)\end{array}$ & $\begin{array}{c}.112 \\
(.0010)\end{array}$ & $\begin{array}{c}. \text { Whites } \\
.058 \\
(.0010)\end{array}$ & $\begin{array}{c}.074 \\
(.0025)\end{array}$ & $\begin{array}{c}.133 \\
(.0024)\end{array}$ & $\begin{array}{c}.138 \\
(.0023)\end{array}$ & $\begin{array}{c}.168 \\
(.0022)\end{array}$ & $\begin{array}{c}.031 \\
(.0024)\end{array}$ \\
\hline \multicolumn{9}{|l|}{ RSN effects (5z): } \\
\hline RSN 1-95 & $\begin{array}{c}.160 \\
(.0015)\end{array}$ & $\begin{array}{c}.128 \\
(.0013)\end{array}$ & $\begin{array}{c}.065 \\
(.0031)\end{array}$ & $\begin{array}{c}.088 \\
(.0031)\end{array}$ & $\begin{array}{c}.154 \\
(.0029)\end{array}$ & $\begin{array}{c}.155 \\
(.0026)\end{array}$ & $\begin{array}{c}.173 \\
(.0026)\end{array}$ & $\begin{array}{c}.032 \\
(.0022)\end{array}$ \\
\hline RSN 96-125 & $\begin{array}{c}.091 \\
(.0023)\end{array}$ & $\begin{array}{c}.082 \\
(.0019)\end{array}$ & $\begin{array}{c}.060 \\
(.0047)\end{array}$ & $\begin{array}{c}.077 \\
(.0046)\end{array}$ & $\begin{array}{c}.131 \\
(.0044)\end{array}$ & $\begin{array}{c}.128 \\
(.0040)\end{array}$ & $\begin{array}{c}.023 \\
(.0034)\end{array}$ & $\begin{array}{c}.0002 \\
(.0031)\end{array}$ \\
\hline RSN 126-160 & $\begin{array}{c}.059 \\
(.0020)\end{array}$ & $\begin{array}{c}.058 \\
(.0017)\end{array}$ & $\begin{array}{c}.054 \\
(.0045)\end{array}$ & $\begin{array}{c}.061 \\
(.0043)\end{array}$ & $\begin{array}{c}.126 \\
(.0041)\end{array}$ & $\begin{array}{c}.050 \\
(.0036)\end{array}$ & $\begin{array}{c}.0084 \\
(.0031)\end{array}$ & $\begin{array}{l}.00002 \\
(.0029)\end{array}$ \\
\hline RSN 161-195 & $\begin{array}{c}.040 \\
(.0020)\end{array}$ & $\begin{array}{c}.044 \\
(.0017)\end{array}$ & $\begin{array}{c}.044 \\
(.0044)\end{array}$ & $\begin{array}{c}.054 \\
(.0043)\end{array}$ & $\begin{array}{c}.102 \\
(.0041)\end{array}$ & $\begin{array}{c}.024 \\
(.0034)\end{array}$ & $\begin{array}{l}-.0013 \\
(.0030)\end{array}$ & $\begin{array}{c}.0017 \\
(.0029)\end{array}$ \\
\hline RSN 196-230 & $\begin{array}{c}.0065 \\
(.0019)\end{array}$ & $\begin{array}{c}.0059 \\
(.0017)\end{array}$ & $\begin{array}{c}.0043 \\
(.0043)\end{array}$ & $\begin{array}{c}.0062 \\
(.0042)\end{array}$ & $\begin{array}{c}.013 \\
(.0038)\end{array}$ & $\begin{array}{c}-.0012 \\
(.0032)\end{array}$ & $\begin{array}{c}.0077 \\
(.0031)\end{array}$ & $\begin{array}{c}.0008 \\
(.0029)\end{array}$ \\
\hline F-statistics & 2403 & 2294 & 111 & 202 & 731 & 861 & 1028 & 50.3 \\
\hline Draft-eligibility effect & $\begin{array}{c}.094 \\
(.0034)\end{array}$ & $\begin{array}{c}.072 \\
(.0028)\end{array}$ & $\begin{array}{c}\text { Nonwhites } \\
.031 \\
\text { (.0069) }\end{array}$ & $\begin{array}{c}.049 \\
(.0065)\end{array}$ & $\begin{array}{c}.090 \\
(.0059)\end{array}$ & $\begin{array}{c}.096 \\
(.0060)\end{array}$ & $\begin{array}{c}.096 \\
(.0063)\end{array}$ & $\begin{array}{c}.027 \\
(.0058)\end{array}$ \\
\hline \multicolumn{9}{|l|}{ RSN effects (5z): } \\
\hline RSN 1-95 & $\begin{array}{c}.100 \\
(.0041)\end{array}$ & $\begin{array}{c}.081 \\
(.0034)\end{array}$ & $\begin{array}{c}.039 \\
(.0086)\end{array}$ & $\begin{array}{c}.059 \\
(.0081)\end{array}$ & $\begin{array}{c}.101 \\
(.0074)\end{array}$ & $\begin{array}{c}.101 \\
(.0072)\end{array}$ & $\begin{array}{c}.099 \\
(.0070)\end{array}$ & $\begin{array}{c}.029 \\
(.0064)\end{array}$ \\
\hline RSN 96-125 & $\begin{array}{c}.062 \\
(.0061)\end{array}$ & $\begin{array}{c}.058 \\
(.0050)\end{array}$ & $\begin{array}{c}.027 \\
(.013)\end{array}$ & $\begin{array}{c}.072 \\
(.012)\end{array}$ & $\begin{array}{c}.089 \\
(.011)\end{array}$ & $\begin{array}{c}.090 \\
(.011)\end{array}$ & $\begin{array}{c}.016 \\
(.0095)\end{array}$ & $\begin{array}{c}.0043 \\
(.0093)\end{array}$ \\
\hline RSN 126-160 & $\begin{array}{c}.044 \\
(.0057)\end{array}$ & $\begin{array}{c}.041 \\
(.0047)\end{array}$ & $\begin{array}{c}.027 \\
(.012)\end{array}$ & $\begin{array}{c}.042 \\
(.012)\end{array}$ & $\begin{array}{c}.093 \\
(.011)\end{array}$ & $\begin{array}{c}.034 \\
(.010)\end{array}$ & $\begin{array}{c}.0052 \\
(.0092)\end{array}$ & $\begin{array}{c}.0018 \\
(.0086)\end{array}$ \\
\hline RSN 161-195 & $\begin{array}{c}.022 \\
(.0055)\end{array}$ & $\begin{array}{c}.021 \\
(.0046)\end{array}$ & $\begin{array}{c}.012 \\
(.012)\end{array}$ & $\begin{array}{c}.027 \\
(.011)\end{array}$ & $\begin{array}{c}.066 \\
(.010)\end{array}$ & $\begin{array}{l}-.0047 \\
.0092\end{array}$ & $\begin{array}{c}.0055 \\
(.0092)\end{array}$ & $\begin{array}{c}.0023 \\
(.0087)\end{array}$ \\
\hline RSN 196-230 & $\begin{array}{c}-.0031 \\
(.0054)\end{array}$ & $\begin{array}{c}.0007 \\
(.0046)\end{array}$ & $\begin{array}{c}-.004 \\
(.012)\end{array}$ & $\begin{array}{c}.018 \\
(.011)\end{array}$ & $\begin{array}{c}.008 \\
(.010)\end{array}$ & $\begin{array}{l}-.010 \\
.0093\end{array}$ & $\begin{array}{l}-.0055 \\
(.0088)\end{array}$ & $\begin{array}{c}.0021 \\
(.0090)\end{array}$ \\
\hline F-statistics & 138 & 134 & 4.98 & 14.3 & 48.9 & 55.1 & 47.3 & 4.51 \\
\hline
\end{tabular}


Table 3. Effects on labor market variables

\begin{tabular}{|c|c|c|c|c|c|c|c|c|}
\hline & \multicolumn{4}{|c|}{$1950-52$} & \multicolumn{4}{|c|}{$1948-52$} \\
\hline & \multirow[b]{2}{*}{$\begin{array}{c}\text { Mean } \\
(1)\end{array}$} & \multirow[b]{2}{*}{$\begin{array}{l}\text { OLS } \\
(2)\end{array}$} & \multicolumn{2}{|c|}{$2 S L S$} & \multirow[b]{2}{*}{$\begin{array}{c}\text { Mean } \\
(5)\end{array}$} & \multirow[b]{2}{*}{$\begin{array}{c}\text { OLS } \\
(6)\end{array}$} & \multicolumn{2}{|c|}{$2 S L S$} \\
\hline & & & $\begin{array}{c}\text { elig } \\
\text { (3) }\end{array}$ & $\begin{array}{l}5 z x \\
(4)\end{array}$ & & & $\begin{array}{l}\text { elig } \\
(7)\end{array}$ & $\begin{array}{c}5 z x \\
(8)\end{array}$ \\
\hline \multicolumn{9}{|c|}{ A. Whites } \\
\hline Work variables in 1999 & & & & & & & & \\
\hline Employment & .861 & $\begin{array}{c}-.020 \\
(.0012)\end{array}$ & $\begin{array}{l}-.0043 \\
(.0072)\end{array}$ & $\begin{array}{l}-.0026 \\
(.0070)\end{array}$ & .855 & $\begin{array}{c}-.010 \\
(.0009)\end{array}$ & $\begin{array}{l}-.0047 \\
(.0072)\end{array}$ & $\begin{array}{l}-.0033 \\
(.0066)\end{array}$ \\
\hline Unemployment & .027 & $\begin{array}{c}.0043 \\
(.0005)\end{array}$ & $\begin{array}{c}.0028 \\
(.0033)\end{array}$ & $\begin{array}{c}.0017 \\
(.0032)\end{array}$ & .027 & $\begin{array}{c}.0028 \\
(.0004)\end{array}$ & $\begin{array}{c}.0022 \\
(.0033)\end{array}$ & $\begin{array}{c}.0014 \\
(.0030)\end{array}$ \\
\hline Not in labor force & .112 & $\begin{array}{c}.016 \\
(.0011)\end{array}$ & $\begin{array}{c}.0014 \\
(.0066)\end{array}$ & $\begin{array}{c}.0009 \\
(.0064)\end{array}$ & .118 & $\begin{array}{c}.0074 \\
(.0008)\end{array}$ & $\begin{array}{c}.0025 \\
(.0066)\end{array}$ & $\begin{array}{c}.0019 \\
(.0060)\end{array}$ \\
\hline Usual hours worked & 41.5 & $\begin{array}{l}-.888 \\
(.054)\end{array}$ & $\begin{array}{l}-.101 \\
(.334)\end{array}$ & $\begin{array}{l}-.230 \\
(.325)\end{array}$ & 41.2 & $\begin{array}{c}-.544 \\
(.040)\end{array}$ & $\begin{array}{c}.055 \\
(.335)\end{array}$ & $\begin{array}{c}-.137 \\
(.305)\end{array}$ \\
\hline Weeks worked & 44.8 & $\begin{array}{l}-.752 \\
(.054)\end{array}$ & $\begin{array}{l}-.133 \\
(.330)\end{array}$ & $\begin{array}{l}-.192 \\
(.321)\end{array}$ & 44.5 & $\begin{array}{l}-.243 \\
(.040)\end{array}$ & $\begin{array}{l}-.120 \\
(.331)\end{array}$ & $\begin{array}{l}-.175 \\
(.301)\end{array}$ \\
\hline \multicolumn{9}{|l|}{ Earnings variables in 1999} \\
\hline Wage and salary income & 46406 & $\begin{array}{r}-8616 \\
(161)\end{array}$ & $\begin{array}{c}-517 \\
(1240)\end{array}$ & $\begin{array}{c}-873 \\
(1209)\end{array}$ & 46595 & $\begin{array}{c}-7936 \\
(128)\end{array}$ & $\begin{array}{c}-115 \\
(1243)\end{array}$ & $\begin{array}{c}-548 \\
(1133)\end{array}$ \\
\hline Log weekly wage & 6.75 & $\begin{array}{c}-.121 \\
(.0026)\end{array}$ & $\begin{array}{r}-.0038 \\
(.016)\end{array}$ & $\begin{array}{l}-.0094 \\
(.016)\end{array}$ & 6.75 & $\begin{array}{c}-.110 \\
(.0019)\end{array}$ & $\begin{array}{c}.009 \\
(.016)\end{array}$ & $\begin{array}{r}-.0030 \\
(.015)\end{array}$ \\
\hline Self employment income & 5261 & $\begin{array}{l}-2772 \\
(77.8)\end{array}$ & $\begin{array}{c}855 \\
(616)\end{array}$ & $\begin{array}{c}867 \\
(606)\end{array}$ & 5285 & $\begin{array}{l}-2846 \\
(62.3)\end{array}$ & $\begin{array}{c}487 \\
(616)\end{array}$ & $\begin{array}{c}668 \\
(567)\end{array}$ \\
\hline \multicolumn{9}{|c|}{ B. Nonwhites } \\
\hline Work variables in 1999 & & & & & & & & \\
\hline Employment & .665 & $\begin{array}{c}.049 \\
(.0040)\end{array}$ & $\begin{array}{c}.018 \\
(.040)\end{array}$ & $\begin{array}{c}.033 \\
(.039)\end{array}$ & .662 & $\begin{array}{c}.063 \\
(.0030)\end{array}$ & $\begin{array}{l}.0013 \\
(.040)\end{array}$ & $\begin{array}{c}.020 \\
(.037)\end{array}$ \\
\hline Unemployment & .056 & $\begin{array}{l}-.0035 \\
(.0019)\end{array}$ & $\begin{array}{l}-.047 \\
(.019)\end{array}$ & $\begin{array}{l}-.048 \\
(.019)\end{array}$ & .054 & $\begin{array}{l}-.0063 \\
(.0014)\end{array}$ & $\begin{array}{l}-.027 \\
(.019)\end{array}$ & $\begin{array}{l}-.036 \\
(.018)\end{array}$ \\
\hline Not in labor force & .279 & $\begin{array}{c}-.045 \\
(.0039)\end{array}$ & $\begin{array}{c}.029 \\
(.039)\end{array}$ & $\begin{array}{c}.015 \\
(.038)\end{array}$ & .284 & $\begin{array}{c}-.057 \\
(.0029)\end{array}$ & $\begin{array}{c}.026 \\
(.039)\end{array}$ & $\begin{array}{c}.016 \\
(.035)\end{array}$ \\
\hline Usual hours worked & 32.8 & $\begin{array}{c}1.97 \\
(.171)\end{array}$ & $\begin{array}{c}3.58 \\
(1.71)\end{array}$ & $\begin{array}{c}4.12 \\
(1.68)\end{array}$ & 32.6 & $\begin{array}{c}2.33 \\
(.129)\end{array}$ & $\begin{array}{c}3.68 \\
(1.73)\end{array}$ & $\begin{array}{c}3.76 \\
(1.57)\end{array}$ \\
\hline Weeks worked & 35.9 & $\begin{array}{c}2.14 \\
(.186)\end{array}$ & $\begin{array}{c}2.84 \\
(1.86)\end{array}$ & $\begin{array}{c}3.15 \\
(1.82)\end{array}$ & 35.7 & $\begin{array}{c}2.73 \\
(.141)\end{array}$ & $\begin{array}{c}2.41 \\
(1.88)\end{array}$ & $\begin{array}{c}2.71 \\
(1.70)\end{array}$ \\
\hline \multicolumn{9}{|l|}{ Earnings variables in 1999} \\
\hline Wage and salary income & 27584 & $\begin{array}{l}1324 \\
(313)\end{array}$ & $\begin{array}{c}3476 \\
(3231)\end{array}$ & $\begin{array}{c}4969 \\
(3199)\end{array}$ & 27711 & $\begin{array}{l}2109 \\
(239)\end{array}$ & $\begin{array}{c}1006 \\
(3255)\end{array}$ & $\begin{array}{c}3314 \\
(2968)\end{array}$ \\
\hline Log weekly wage & 6.41 & $\begin{array}{c}.028 \\
(.0074)\end{array}$ & $\begin{array}{l}-.037 \\
(.067)\end{array}$ & $\begin{array}{c}.012 \\
(.065)\end{array}$ & 6.43 & $\begin{array}{c}.042 \\
(.0057)\end{array}$ & $\begin{array}{r}-.0090 \\
(.067)\end{array}$ & $\begin{array}{c}.019 \\
(.060)\end{array}$ \\
\hline Self employment income & 1709 & $\begin{array}{l}-616 \\
(108)\end{array}$ & $\begin{array}{c}328 \\
(1177)\end{array}$ & $\begin{array}{c}436 \\
(1147)\end{array}$ & 1708 & $\begin{array}{c}-511 \\
(82.4)\end{array}$ & $\begin{array}{c}1750 \\
(1167)\end{array}$ & $\begin{array}{c}1115 \\
(1077)\end{array}$ \\
\hline
\end{tabular}

Note: All regressions include a full set of dummies for state of birth, year of birth and month of birth. Columns 3-4 and 7-8 report 2SLS estimates with the instrument sets listed. Robust standard errors are reported in parentheses. Estimates computed using sampling weights. 
Table 4a: Effects on education, by race and by year of birth

\begin{tabular}{|c|c|c|c|c|c|c|c|c|}
\hline & \multicolumn{4}{|c|}{$1950-52$} & \multicolumn{4}{|c|}{$1948-52$} \\
\hline & \multirow[b]{2}{*}{$\begin{array}{l}\text { Mean } \\
(1)\end{array}$} & \multirow[b]{2}{*}{$\begin{array}{l}\text { OLS } \\
(2)\end{array}$} & \multicolumn{2}{|c|}{$2 S L S$} & \multirow[b]{2}{*}{$\begin{array}{c}\text { Mean } \\
(5)\end{array}$} & \multirow[b]{2}{*}{$\begin{array}{c}\text { OLS } \\
(6) \\
\end{array}$} & \multicolumn{2}{|c|}{ 2SLS } \\
\hline & & & $\begin{array}{l}\text { elig } \\
\text { (3) }\end{array}$ & $\begin{array}{l}5 \mathrm{zX} \\
(4)\end{array}$ & & & $\begin{array}{l}\text { elig } \\
\text { (7) }\end{array}$ & $\begin{array}{c}5 \mathrm{zx} \\
(8)\end{array}$ \\
\hline \multicolumn{9}{|c|}{ A. Whites } \\
\hline Years of schooling (imputed) & 13.8 & $\begin{array}{c}-.551 \\
(.0074)\end{array}$ & $\begin{array}{c}.332 \\
(.053)\end{array}$ & $\begin{array}{c}.336 \\
(.052)\end{array}$ & 13.8 & $\begin{array}{c}-.550 \\
(.0057)\end{array}$ & $\begin{array}{c}.294 \\
(.053)\end{array}$ & $\begin{array}{c}.314 \\
(.049)\end{array}$ \\
\hline Years of college & 1.73 & $\begin{array}{l}-.512 \\
(.0050)\end{array}$ & $\begin{array}{c}.265 \\
(.035)\end{array}$ & $\begin{array}{c}.261 \\
(.034)\end{array}$ & 1.76 & $\begin{array}{l}-.534 \\
(.0038)\end{array}$ & $\begin{array}{c}.238 \\
(.034)\end{array}$ & $\begin{array}{c}.248 \\
(.032)\end{array}$ \\
\hline 9th grade + & .977 & $\begin{array}{c}.015 \\
(.0004)\end{array}$ & $\begin{array}{c}.0056 \\
(.0031)\end{array}$ & $\begin{array}{c}.0061 \\
(.0030)\end{array}$ & .975 & $\begin{array}{c}.020 \\
(.0003)\end{array}$ & $\begin{array}{c}.0021 \\
(.0031)\end{array}$ & $\begin{array}{c}.0040 \\
(.0028)\end{array}$ \\
\hline 10th grade + & .965 & $\begin{array}{c}.018 \\
(.0005)\end{array}$ & $\begin{array}{c}.0080 \\
(.0037)\end{array}$ & $\begin{array}{c}.0083 \\
(.0036)\end{array}$ & .963 & $\begin{array}{c}.025 \\
(.0004)\end{array}$ & $\begin{array}{c}.0042 \\
(.0038)\end{array}$ & $\begin{array}{c}.0062 \\
(.0034)\end{array}$ \\
\hline 11th grade + & .948 & $\begin{array}{c}.021 \\
(.0007)\end{array}$ & $\begin{array}{c}.012 \\
(.0045)\end{array}$ & $\begin{array}{c}.013 \\
(.0044)\end{array}$ & .946 & $\begin{array}{c}.029 \\
(.0005)\end{array}$ & $\begin{array}{c}.0071 \\
(.0045)\end{array}$ & $\begin{array}{c}.010 \\
(.0041)\end{array}$ \\
\hline 12th grade (no diploma) + & .931 & $\begin{array}{c}.024 \\
(.0008)\end{array}$ & $\begin{array}{c}.015 \\
(.0051)\end{array}$ & $\begin{array}{c}.016 \\
(.0049)\end{array}$ & .930 & $\begin{array}{c}.033 \\
(.0006)\end{array}$ & $\begin{array}{c}.009 \\
(.0050)\end{array}$ & $\begin{array}{c}.013 \\
(.0046)\end{array}$ \\
\hline High school graduate or higher + & .910 & $\begin{array}{c}.025 \\
(.0009)\end{array}$ & $\begin{array}{c}.023 \\
(.0057)\end{array}$ & $\begin{array}{c}.023 \\
(.0056)\end{array}$ & .908 & $\begin{array}{c}.034 \\
(.0006)\end{array}$ & $\begin{array}{c}.017 \\
(.0057)\end{array}$ & $\begin{array}{c}.020 \\
(.0052)\end{array}$ \\
\hline Some college (less than 1 year) + & .655 & $\begin{array}{c}-.050 \\
(.0015)\end{array}$ & $\begin{array}{c}.079 \\
(.009)\end{array}$ & $\begin{array}{c}.079 \\
(.0093)\end{array}$ & .659 & $\begin{array}{c}-.048 \\
(.0011)\end{array}$ & $\begin{array}{c}.064 \\
(.0094)\end{array}$ & $\begin{array}{c}.070 \\
(.0086)\end{array}$ \\
\hline 1 or more years of college (no degree) + & .582 & $\begin{array}{c}-.082 \\
(.0016)\end{array}$ & $\begin{array}{c}.090 \\
(.010)\end{array}$ & $\begin{array}{c}.089 \\
(.010)\end{array}$ & .588 & $\begin{array}{c}-.083 \\
(.0012)\end{array}$ & $\begin{array}{c}.074 \\
(.010)\end{array}$ & $\begin{array}{c}.080 \\
(.0090)\end{array}$ \\
\hline Associate's degree + & .411 & $\begin{array}{c}-.126 \\
(.0015)\end{array}$ & $\begin{array}{c}.081 \\
(.010)\end{array}$ & $\begin{array}{c}.079 \\
(.010)\end{array}$ & .419 & $\begin{array}{c}-.133 \\
(.0011)\end{array}$ & $\begin{array}{c}.074 \\
(.010)\end{array}$ & $\begin{array}{c}.076 \\
(.0091)\end{array}$ \\
\hline Bachelor's degree + & .333 & $\begin{array}{l}-.168 \\
(.0014)\end{array}$ & $\begin{array}{c}.053 \\
(.010)\end{array}$ & $\begin{array}{c}.051 \\
(.0094)\end{array}$ & .341 & $\begin{array}{c}-.176 \\
(.0010)\end{array}$ & $\begin{array}{c}.051 \\
(.010)\end{array}$ & $\begin{array}{c}.051 \\
(.0088)\end{array}$ \\
\hline Master's degree + & .135 & $\begin{array}{c}-.082 \\
(.0009)\end{array}$ & $\begin{array}{c}.016 \\
(.0070)\end{array}$ & $\begin{array}{c}.017 \\
(.0068)\end{array}$ & .140 & $\begin{array}{c}-.090 \\
(.0007)\end{array}$ & $\begin{array}{c}.019 \\
(.0070)\end{array}$ & $\begin{array}{c}.018 \\
(.0064)\end{array}$ \\
\hline Professional degree+ & .051 & $\begin{array}{c}-.043 \\
(.0005)\end{array}$ & $\begin{array}{c}.0047 \\
(.0045)\end{array}$ & $\begin{array}{c}.0037 \\
(.0044)\end{array}$ & .052 & $\begin{array}{l}-.046 \\
(.0004)\end{array}$ & $\begin{array}{c}.010 \\
(.0045)\end{array}$ & $\begin{array}{c}.0057 \\
(.0041)\end{array}$ \\
\hline
\end{tabular}

(Continued) 
Table 4a: Estimates of effects of military services in Vietnam era on education, by race and by year of birth, continued

\begin{tabular}{|c|c|c|c|c|c|c|c|c|}
\hline & \multicolumn{4}{|c|}{$1950-52$} & \multicolumn{4}{|c|}{$1948-52$} \\
\hline & \multirow[b]{2}{*}{$\begin{array}{c}\text { Mean } \\
(1) \\
\end{array}$} & \multirow[b]{2}{*}{$\begin{array}{l}\text { OLS } \\
(2)\end{array}$} & \multicolumn{2}{|c|}{ 2SLS } & \multirow[b]{2}{*}{$\begin{array}{c}\text { Mean } \\
(6) \\
\end{array}$} & \multirow[b]{2}{*}{$\begin{array}{c}\text { OLS } \\
(7) \\
\end{array}$} & \multicolumn{2}{|c|}{ 2SLS } \\
\hline & & & $\begin{array}{l}\text { elig } \\
\text { (3) }\end{array}$ & $\begin{array}{c}5 z x \\
(5) \\
\end{array}$ & & & $\begin{array}{l}\text { elig } \\
(8)\end{array}$ & $\begin{array}{c}5 z x \\
(10) \\
\end{array}$ \\
\hline \multicolumn{9}{|c|}{ B. Nonwhites } \\
\hline Years of schooling (imputed) & 12.6 & $\begin{array}{c}.512 \\
(.020)\end{array}$ & $\begin{array}{c}.203 \\
(.230)\end{array}$ & $\begin{array}{l}.190 \\
(.226)\end{array}$ & 12.6 & $\begin{array}{c}.643 \\
(.016)\end{array}$ & $\begin{array}{l}.184 \\
(.235)\end{array}$ & $\begin{array}{l}.196 \\
(.211)\end{array}$ \\
\hline Years of college & 1.02 & $\begin{array}{c}.118 \\
(.0116)\end{array}$ & $\begin{array}{c}.192 \\
(.118)\end{array}$ & $\begin{array}{l}.173 \\
(.115)\end{array}$ & 1.02 & $\begin{array}{c}.150 \\
(.0088)\end{array}$ & $\begin{array}{l}.159 \\
(.119)\end{array}$ & $\begin{array}{c}.162 \\
(.108)\end{array}$ \\
\hline 9th grade + & .948 & $\begin{array}{c}.043 \\
(.0016)\end{array}$ & $\begin{array}{l}.0013 \\
(.019)\end{array}$ & $\begin{array}{l}.0003 \\
(.019)\end{array}$ & .944 & $\begin{array}{c}.055 \\
(.0013)\end{array}$ & $\begin{array}{l}-.009 \\
(.020)\end{array}$ & $\begin{array}{l}-.0018 \\
(.018)\end{array}$ \\
\hline 10th grade + & .923 & $\begin{array}{c}.063 \\
(.0019)\end{array}$ & $\begin{array}{l}-.0056 \\
(.023)\end{array}$ & $\begin{array}{l}-.0044 \\
(.022)\end{array}$ & .918 & $\begin{array}{c}.079 \\
(.0015)\end{array}$ & $\begin{array}{l}-.015 \\
(.023)\end{array}$ & $\begin{array}{l}-.0050 \\
(.021)\end{array}$ \\
\hline 11th grade + & .882 & $\begin{array}{c}.090 \\
(.0023)\end{array}$ & $\begin{array}{c}.019 \\
(.027)\end{array}$ & $\begin{array}{c}.019 \\
(.027)\end{array}$ & .876 & $\begin{array}{c}.110 \\
(.0018)\end{array}$ & $\begin{array}{c}.016 \\
(.028)\end{array}$ & $\begin{array}{c}.025 \\
(.025)\end{array}$ \\
\hline 12th grade (no diploma) + & .832 & $\begin{array}{c}.122 \\
(.0027)\end{array}$ & $\begin{array}{l}-.0021 \\
(.032)\end{array}$ & $\begin{array}{l}-.0027 \\
(.031)\end{array}$ & .826 & $\begin{array}{c}.144 \\
(.0021)\end{array}$ & $\begin{array}{l}-.014 \\
(.032)\end{array}$ & $\begin{array}{l}.0039 \\
(.029)\end{array}$ \\
\hline High school graduate or higher + & .770 & $\begin{array}{c}.147 \\
(.0032)\end{array}$ & $\begin{array}{c}.055 \\
(.035)\end{array}$ & $\begin{array}{c}.055 \\
(.034)\end{array}$ & .766 & $\begin{array}{c}.170 \\
(.0024)\end{array}$ & $\begin{array}{c}.045 \\
(.035)\end{array}$ & $\begin{array}{c}.058 \\
(.032)\end{array}$ \\
\hline Some college (less than 1 year) + & .468 & $\begin{array}{c}.158 \\
(.0042)\end{array}$ & $\begin{array}{c}.080 \\
(.041)\end{array}$ & $\begin{array}{c}.083 \\
(.040)\end{array}$ & .468 & $\begin{array}{c}.171 \\
(.0031)\end{array}$ & $\begin{array}{c}.094 \\
(.041)\end{array}$ & $\begin{array}{c}.092 \\
(.037)\end{array}$ \\
\hline 1 or more years of college (no degree) + & .400 & $\begin{array}{c}.117 \\
(.0042)\end{array}$ & $\begin{array}{c}.070 \\
(.040)\end{array}$ & $\begin{array}{c}.068 \\
(.040)\end{array}$ & .400 & $\begin{array}{c}.132 \\
(.0032)\end{array}$ & $\begin{array}{c}.054 \\
(.041)\end{array}$ & $\begin{array}{c}.065 \\
(.037)\end{array}$ \\
\hline Associate's degree + & .226 & $\begin{array}{c}.024 \\
(.0036)\end{array}$ & $\begin{array}{c}.055 \\
(.035)\end{array}$ & $\begin{array}{c}.051 \\
(.034)\end{array}$ & .228 & $\begin{array}{c}.031 \\
(.0027)\end{array}$ & $\begin{array}{c}.042 \\
(.035)\end{array}$ & $\begin{array}{c}.051 \\
(.032)\end{array}$ \\
\hline Bachelor's degree + & .160 & $\begin{array}{c}-.032 \\
(.0030)\end{array}$ & $\begin{array}{c}.028 \\
(.031)\end{array}$ & $\begin{array}{c}.019 \\
(.030)\end{array}$ & .163 & $\begin{array}{c}-.026 \\
(.0023)\end{array}$ & $\begin{array}{c}.012 \\
(.031)\end{array}$ & $\begin{array}{c}.010 \\
(.028)\end{array}$ \\
\hline Master's degree + & .057 & $\begin{array}{c}-.020 \\
(.0018)\end{array}$ & $\begin{array}{l}.0080 \\
(.019)\end{array}$ & $\begin{array}{l}.0067 \\
(.019)\end{array}$ & .060 & $\begin{array}{c}-.021 \\
(.0014)\end{array}$ & $\begin{array}{c}.020 \\
(.020)\end{array}$ & $\begin{array}{c}.011 \\
(.018)\end{array}$ \\
\hline Professional degree+ & .018 & $\begin{array}{c}-.012 \\
(.0010)\end{array}$ & $\begin{array}{l}-.0028 \\
(.011)\end{array}$ & $\begin{array}{l}-.0026 \\
(.011)\end{array}$ & .019 & $\begin{array}{c}-.012 \\
(.0008)\end{array}$ & $\begin{array}{l}.0086 \\
(.011)\end{array}$ & $\begin{array}{l}.0018 \\
(.010)\end{array}$ \\
\hline
\end{tabular}

Note: All regressions include a full set of dummies for state of birth, year of birth and month of birth. Columns 3-5 and 8-10 report 2SLS estimates with the instrument sets listed. Robust standard errors are reported in parentheses. Estimates computed using sampling weights. 
Table 4b: 2SLS Estimates of effects on schooling, by race and single year of birth

\begin{tabular}{|c|c|c|c|c|c|}
\hline & $\begin{array}{c}1948 \\
(1)\end{array}$ & $\begin{array}{c}1949 \\
(2)\end{array}$ & $\begin{array}{c}1950 \\
(3)\end{array}$ & $\begin{array}{c}1951 \\
(4)\end{array}$ & $\begin{array}{c}1952 \\
(5)\end{array}$ \\
\hline \multicolumn{6}{|c|}{ A. Whites } \\
\hline \multirow[t]{2}{*}{ Years of schooling (imputed) } & .179 & .132 & .233 & .455 & .314 \\
\hline & $(.231)$ & $(.173)$ & $(.098)$ & $(.093)$ & $(.085)$ \\
\hline \multirow[t]{2}{*}{ Years of college } & .050 & .200 & .219 & .354 & .215 \\
\hline & $(.147)$ & $(.111)$ & $(.063)$ & $(.061)$ & $(.054)$ \\
\hline \multirow[t]{2}{*}{1 or more years of college (no degree) + } & .005 & .019 & .088 & .105 & .068 \\
\hline & $(.041)$ & $(.031)$ & $(.018)$ & $(.017)$ & $(.016)$ \\
\hline \multirow[t]{2}{*}{ Associate's degree + } & .004 & .080 & .072 & .102 & .067 \\
\hline & $(.042)$ & $(.032)$ & $(.018)$ & $(.018)$ & $(.016)$ \\
\hline \multirow[t]{2}{*}{ Bachelor's degree + } & .015 & .061 & .038 & .075 & .044 \\
\hline & $(.041)$ & $(.031)$ & $(.018)$ & $(.017)$ & $(.015)$ \\
\hline \multirow[t]{2}{*}{ Master's degree + } & .030 & .021 & -.004 & .029 & .024 \\
\hline & $(.031)$ & $(.023)$ & $(.013)$ & $(.012)$ & $(.011)$ \\
\hline \multicolumn{6}{|c|}{ B. Nonwhites } \\
\hline \multirow[t]{2}{*}{ Years of schooling (imputed) } & 1.129 & -.238 & .006 & .338 & .028 \\
\hline & (1.139) & $(.708)$ & $(.397)$ & $(.383)$ & $(.416)$ \\
\hline \multirow[t]{2}{*}{ Years of college } & .109 & -.023 & .065 & .072 & .257 \\
\hline & $(.584)$ & $(.352)$ & $(.203)$ & $(.198)$ & $(.207)$ \\
\hline \multirow[t]{2}{*}{1 or more years of college (no degree) + } & .015 & .040 & .003 & .052 & .122 \\
\hline & (.198) & $(.119)$ & $(.069)$ & $(.068)$ & $(.072)$ \\
\hline \multirow[t]{2}{*}{ Associate's degree + } & .018 & .031 & -.004 & .050 & .066 \\
\hline & $(.172)$ & $(.104)$ & $(.060)$ & $(.058)$ & $(.061)$ \\
\hline \multirow[t]{2}{*}{ Bachelor's degree + } & -.073 & -.087 & .021 & -.0220 & .0330 \\
\hline & $(.152)$ & $(.091)$ & $(.052)$ & $(.051)$ & $(.054)$ \\
\hline \multirow[t]{2}{*}{ Master's degree + } & .112 & .022 & .023 & -.029 & .027 \\
\hline & $(.107)$ & $(.060)$ & $(.034)$ & $(.032)$ & $(.032)$ \\
\hline
\end{tabular}

Note: The table reports 2SLS estimates of schooling effects by single year of birth using the $5 z$ instrument set. All regressions include a full set of dummies for state of birth, year of birth, and month of birth. Robust standard errors in parentheses. Estimates were computed using sampling weights. 
Table 5: Effects on disability status and disability-income variables, for men born 1948-52

\begin{tabular}{|c|c|c|c|c|c|c|c|c|}
\hline & \multicolumn{4}{|c|}{ Whites } & \multicolumn{4}{|c|}{ Nonwhites } \\
\hline & \multirow[b]{2}{*}{$\begin{array}{c}\text { Mean } \\
\text { (1) }\end{array}$} & \multirow[b]{2}{*}{$\begin{array}{l}\text { OLS } \\
(2)\end{array}$} & \multicolumn{2}{|c|}{ 2SLS } & \multirow[b]{2}{*}{$\begin{array}{l}\text { Mean } \\
\text { (5) }\end{array}$} & \multirow[b]{2}{*}{$\begin{array}{l}\text { OLS } \\
(6)\end{array}$} & \multicolumn{2}{|c|}{ 2SLS } \\
\hline & & & $\begin{array}{l}\text { elig } \\
\text { (3) }\end{array}$ & $\begin{array}{l}5 z x \\
(4)\end{array}$ & & & $\begin{array}{l}\text { elig } \\
\text { (7) }\end{array}$ & $\begin{array}{l}5 z x \\
(8)\end{array}$ \\
\hline & \multicolumn{8}{|c|}{ A. Disability variables } \\
\hline Work disability & .124 & $\begin{array}{c}.013 \\
(.0008)\end{array}$ & $\begin{array}{c}-.0005 \\
(.0066)\end{array}$ & $\begin{array}{c}-.0007 \\
(.0061)\end{array}$ & .212 & $\begin{array}{c}-.010 \\
(.0026)\end{array}$ & $\begin{array}{l}-.045 \\
(.034)\end{array}$ & $\begin{array}{l}-.054 \\
(.031)\end{array}$ \\
\hline Non-work disability & .074 & $\begin{array}{c}.011 \\
(.0006)\end{array}$ & $\begin{array}{c}.013 \\
(.0053)\end{array}$ & $\begin{array}{c}.014 \\
(.0048)\end{array}$ & .120 & $\begin{array}{l}-.0013 \\
(.0021)\end{array}$ & $\begin{array}{l}-.016 \\
(.028)\end{array}$ & $\begin{array}{l}-.0062 \\
(.026)\end{array}$ \\
\hline Mobility & .086 & $\begin{array}{c}.018 \\
(.0007)\end{array}$ & $\begin{array}{c}.0085 \\
(.0057)\end{array}$ & $\begin{array}{c}.012 \\
(.0051)\end{array}$ & .139 & $\begin{array}{c}.0055 \\
(.0023)\end{array}$ & $\begin{array}{l}-.028 \\
(.029)\end{array}$ & $\begin{array}{l}-.030 \\
(.026)\end{array}$ \\
\hline Self care & .022 & $\begin{array}{l}.00002 \\
(.0004)\end{array}$ & $\begin{array}{c}.0074 \\
(.0030)\end{array}$ & $\begin{array}{c}.0077 \\
(.0028)\end{array}$ & .042 & $\begin{array}{l}-.0085 \\
(.0013)\end{array}$ & $\begin{array}{c}.011 \\
(.017)\end{array}$ & $\begin{array}{l}-.0011 \\
(.016)\end{array}$ \\
\hline Physical & .052 & $\begin{array}{c}.0013 \\
(.0005)\end{array}$ & $\begin{array}{l}.0050 \\
(.0045)\end{array}$ & $\begin{array}{c}.0046 \\
(.0042)\end{array}$ & .122 & $\begin{array}{c}-.014 \\
(.0021)\end{array}$ & $\begin{array}{l}-.0080 \\
(.028)\end{array}$ & $\begin{array}{l}-.0080 \\
(.025)\end{array}$ \\
\hline Mental & .045 & $\begin{array}{c}.0033 \\
(.0005)\end{array}$ & $\begin{array}{c}.0069 \\
(.0043)\end{array}$ & $\begin{array}{c}.0055 \\
(.0039)\end{array}$ & .076 & $\begin{array}{l}-.0066 \\
(.0017)\end{array}$ & $\begin{array}{c}.015 \\
(.023)\end{array}$ & $\begin{array}{c}.011 \\
(.021)\end{array}$ \\
\hline Vision or hearing & .038 & $\begin{array}{c}.0050 \\
(.0005)\end{array}$ & $\begin{array}{c}.011 \\
(.0039)\end{array}$ & $\begin{array}{c}.012 \\
(.0035)\end{array}$ & .048 & $\begin{array}{l}-.0032 \\
(.0014)\end{array}$ & $\begin{array}{c}.039 \\
(.018)\end{array}$ & $\begin{array}{c}.036 \\
(.016)\end{array}$ \\
\hline & B. Disab & ty-income & variables & & & & & \\
\hline Other income (incl. VDC) & 440 & $\begin{array}{c}499 \\
(9.14)\end{array}$ & $\begin{array}{c}302 \\
(69.2)\end{array}$ & $\begin{array}{c}266 \\
(62.6)\end{array}$ & 628 & $\begin{array}{c}743 \\
(29.3)\end{array}$ & $\begin{array}{c}764 \\
(320)\end{array}$ & $\begin{array}{c}540 \\
(273)\end{array}$ \\
\hline Other income $>0$ & .059 & $\begin{array}{c}.072 \\
(.0007)\end{array}$ & $\begin{array}{c}.042 \\
(.0047)\end{array}$ & $\begin{array}{c}.040 \\
(.0042)\end{array}$ & .078 & $\begin{array}{c}.087 \\
(.0020)\end{array}$ & $\begin{array}{c}.034 \\
(.022)\end{array}$ & $\begin{array}{c}.040 \\
(.020)\end{array}$ \\
\hline Retirement/Dis. income (incl. MDP) & 855 & $\begin{array}{c}947 \\
(18.1)\end{array}$ & $\begin{array}{c}563 \\
(129)\end{array}$ & $\begin{array}{c}475 \\
(109)\end{array}$ & 973 & $\begin{array}{c}956 \\
(51.6)\end{array}$ & $\begin{array}{l}1015 \\
(590)\end{array}$ & $\begin{array}{c}847 \\
(458)\end{array}$ \\
\hline Retirement/Dis. income $>0$ & .051 & $\begin{array}{c}.057 \\
(.0006)\end{array}$ & $\begin{array}{c}.030 \\
(.0044)\end{array}$ & $\begin{array}{c}.031 \\
(.0039)\end{array}$ & .071 & $\begin{array}{c}.067 \\
(.0019)\end{array}$ & $\begin{array}{c}.063 \\
(.021)\end{array}$ & $\begin{array}{c}.052 \\
(.019)\end{array}$ \\
\hline
\end{tabular}

Note: All regressions include a full set of dummies for state of birth, year of birth and month of birth. Columns 3-4 and 7-8 report 2SLS estimates with the instrument sets listed. Robust standard errors are reported in parentheses. Estimates computed using sampling weights. 
Table 6. Wage equations for white men born 1948-52

\begin{tabular}{|c|c|c|c|c|c|c|c|c|}
\hline & \multirow[b]{3}{*}{$\begin{array}{l}\text { OLS } \\
(1)\end{array}$} & \multicolumn{7}{|c|}{ Instrumental variables estimates } \\
\hline & & \multirow{2}{*}{$\begin{array}{c}\text { Elig+age } \\
2 S L S \\
(2)\end{array}$} & \multicolumn{2}{|c|}{ Elig+yob } & \multicolumn{2}{|c|}{$5 z \mathrm{zx}$} & \multicolumn{2}{|c|}{$7 \mathrm{zx}$} \\
\hline & & & $\begin{array}{c}\text { 2SLS } \\
(3)\end{array}$ & $\begin{array}{c}\text { LIML } \\
(4)\end{array}$ & $\begin{array}{c}\text { 2SLS } \\
(5) \\
\end{array}$ & $\begin{array}{c}\text { LIML } \\
(6) \\
\end{array}$ & $\begin{array}{c}\text { 2SLS } \\
(7)\end{array}$ & $\begin{array}{c}\text { LIML } \\
(8) \\
\end{array}$ \\
\hline \multicolumn{9}{|l|}{ First stage F-statistics } \\
\hline All instruments & - & 155 & 93.3 & - & 16.8 & - & 12.7 & - \\
\hline RSN instruments & - & 38.8 & 39.4 & - & 2.45 & - & 1.95 & - \\
\hline Adjusted multivariate $\mathrm{F}$ & - & 24.5 & 15.0 & - & 3.61 & - & 2.89 & - \\
\hline Second Stage Estimates & \multicolumn{8}{|c|}{ A. Without non-work disability controls } \\
\hline Years of schooling (imputed) & $\begin{array}{c}.118 \\
(.0007)\end{array}$ & $\begin{array}{l}.070 \\
(.035)\end{array}$ & $\begin{array}{c}.078 \\
(.034)\end{array}$ & $\begin{array}{c}.075 \\
(.037)\end{array}$ & $\begin{array}{c}.043 \\
(.030)\end{array}$ & $\begin{array}{l}.0066 \\
(.047)\end{array}$ & $\begin{array}{l}.051 \\
(.028)\end{array}$ & $\begin{array}{l}.0025 \\
(.054)\end{array}$ \\
\hline $\begin{array}{l}\text { Veteran-adjusted potential experience } \\
=\text { age-educ-6-2*vet }\end{array}$ & $\begin{array}{c}-.057 \\
(.0048)\end{array}$ & $\begin{array}{l}-.0036 \\
(.031)\end{array}$ & $\begin{array}{l}-.015 \\
(.040)\end{array}$ & $\begin{array}{l}-.015 \\
(.040)\end{array}$ & $\begin{array}{c}.011 \\
(.038)\end{array}$ & $\begin{array}{c}.010 \\
(.040)\end{array}$ & $\begin{array}{c}.017 \\
(.038)\end{array}$ & $\begin{array}{c}.015 \\
(.040)\end{array}$ \\
\hline Potential experience squared & $\begin{array}{c}.0011 \\
(.0001)\end{array}$ & $\begin{array}{c}.0002 \\
(.0005)\end{array}$ & $\begin{array}{c}.0004 \\
(.0007)\end{array}$ & $\begin{array}{c}.0004 \\
(.0007)\end{array}$ & $\begin{array}{c}-.0001 \\
(.0007)\end{array}$ & $\begin{array}{c}.000001 \\
(.0007)\end{array}$ & $\begin{array}{c}-.0002 \\
(.0007)\end{array}$ & $\begin{array}{l}-.0001 \\
(.0007)\end{array}$ \\
\hline Experience derivative & $\begin{array}{c}.0090 \\
(.0006)\end{array}$ & $\begin{array}{c}.0069 \\
(.0019)\end{array}$ & $\begin{array}{c}.0066 \\
(.0018)\end{array}$ & $\begin{array}{c}.0067 \\
(.0020)\end{array}$ & $\begin{array}{c}.0082 \\
(.0017)\end{array}$ & $\begin{array}{c}.010 \\
(.0025)\end{array}$ & $\begin{array}{c}.0078 \\
(.0016)\end{array}$ & $\begin{array}{c}.010 \\
(.0028)\end{array}$ \\
\hline Implicit veteran effect & $\begin{array}{c}-.016 \\
(.0011)\end{array}$ & $\begin{array}{c}-.013 \\
(.0038)\end{array}$ & $\begin{array}{c}-.013 \\
(.0038)\end{array}$ & $\begin{array}{c}-.013 \\
(.0040)\end{array}$ & $\begin{array}{c}-.017 \\
(.0033)\end{array}$ & $\begin{array}{c}-.020 \\
(.0048)\end{array}$ & $\begin{array}{c}-.016 \\
(.0032)\end{array}$ & $\begin{array}{c}-.021 \\
(.0054)\end{array}$ \\
\hline & \multicolumn{8}{|c|}{ B. Using disability-adjusted log wage } \\
\hline Years of schooling (imputed) & $\begin{array}{c}.116 \\
(.0007)\end{array}$ & $\begin{array}{c}.077 \\
(.035)\end{array}$ & $\begin{array}{c}.084 \\
(.034)\end{array}$ & $\begin{array}{c}.082 \\
(.037)\end{array}$ & $\begin{array}{c}.048 \\
(.030)\end{array}$ & $\begin{array}{c}.014 \\
(.047)\end{array}$ & $\begin{array}{c}.056 \\
(.028)\end{array}$ & $\begin{array}{c}.012 \\
(.053)\end{array}$ \\
\hline Reduced-form veteran effect & $\begin{array}{c}-.017 \\
(.0011) \\
\end{array}$ & $\begin{array}{c}-.014 \\
(.0037)\end{array}$ & $\begin{array}{c}-.013 \\
(.0037)\end{array}$ & $\begin{array}{c}-.013 \\
(.0040)\end{array}$ & $\begin{array}{c}-.017 \\
(.0033)\end{array}$ & $\begin{array}{c}-.020 \\
(.0048)\end{array}$ & $\begin{array}{c}-.016 \\
(.0032)\end{array}$ & $\begin{array}{c}-.021 \\
(.0054)\end{array}$ \\
\hline
\end{tabular}

Notes: The table reports estimates of the structural wage equation described in the text. The average experience in the sample is 28.85 and average schooling is 13.8 . 

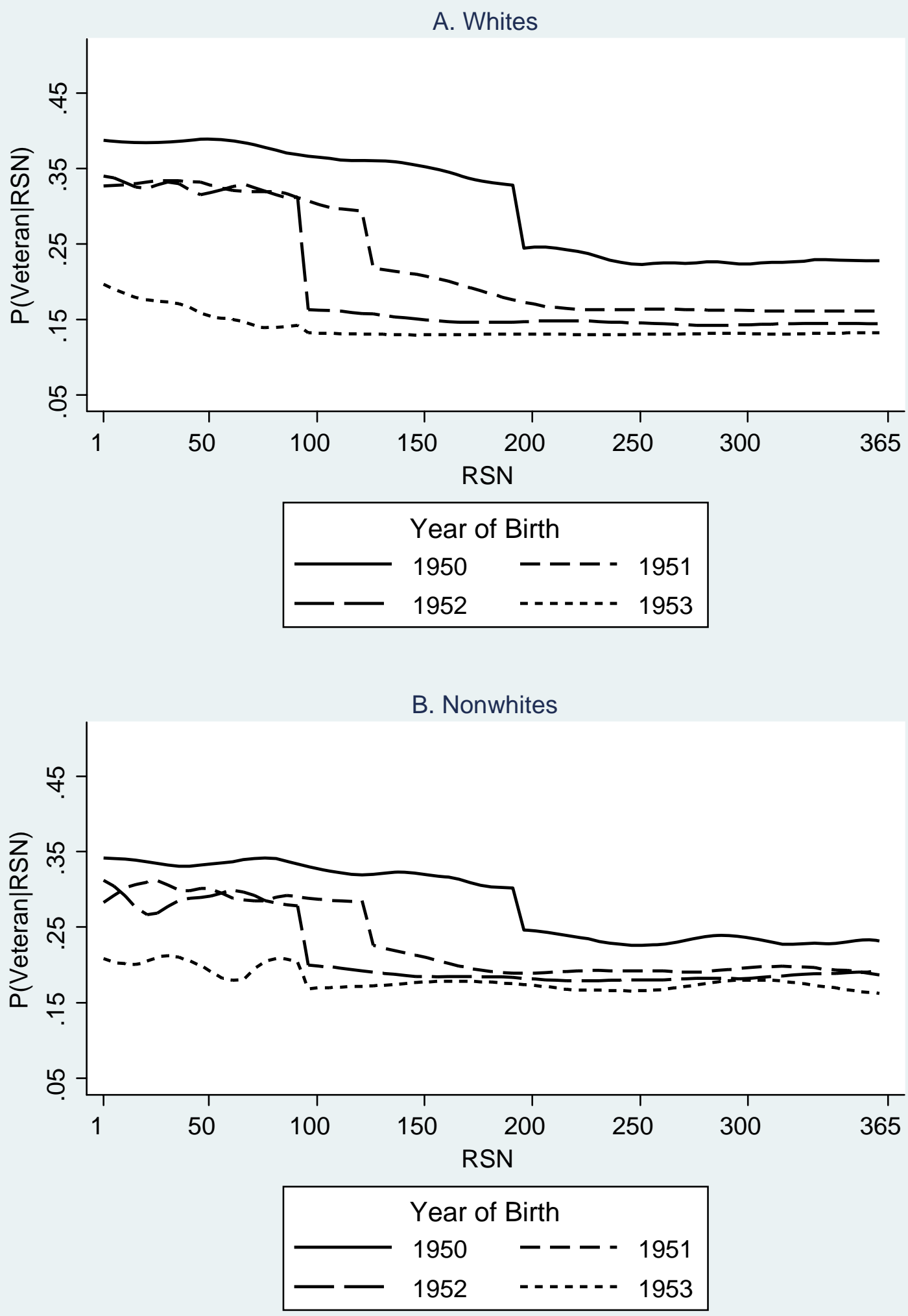

Figure 1. First-stage plots (bandwidth $=4$ ). The relation between probability of military service and draft lottery numbers. Data from the 2000 Census. 

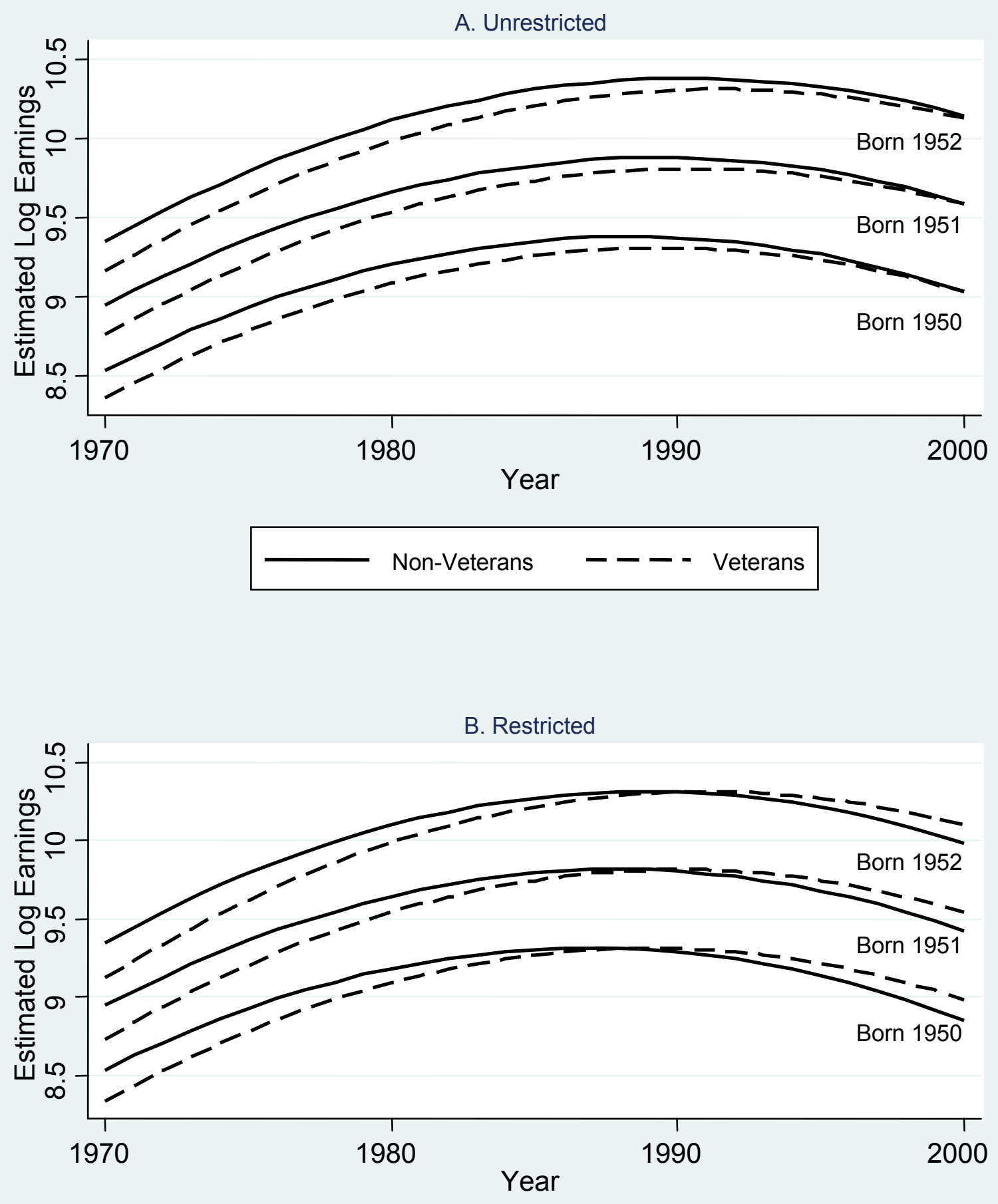

Figure 2. The Effect of Veteran Status on Experience Profiles 
A. Whites

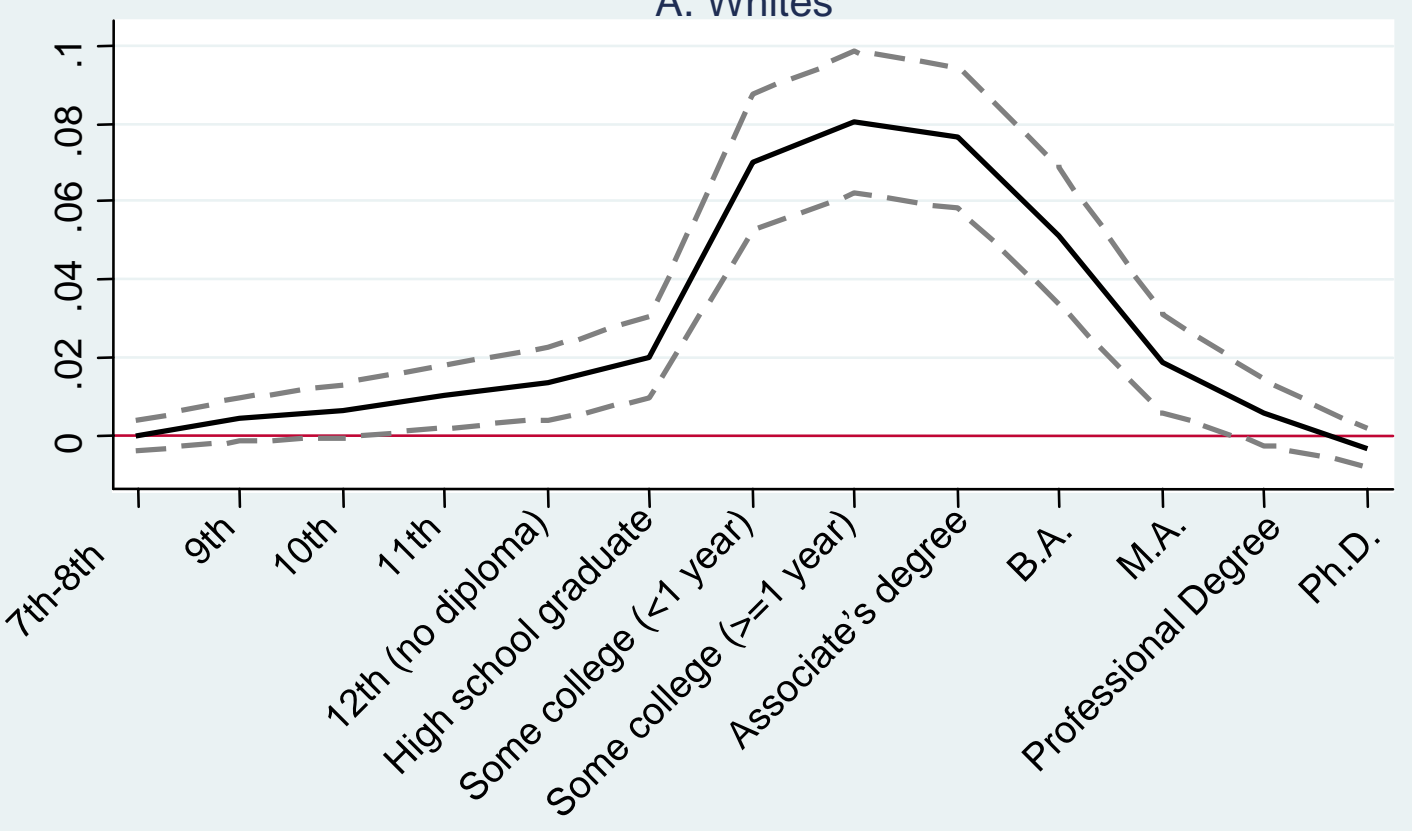

\section{B. Nonwhites}

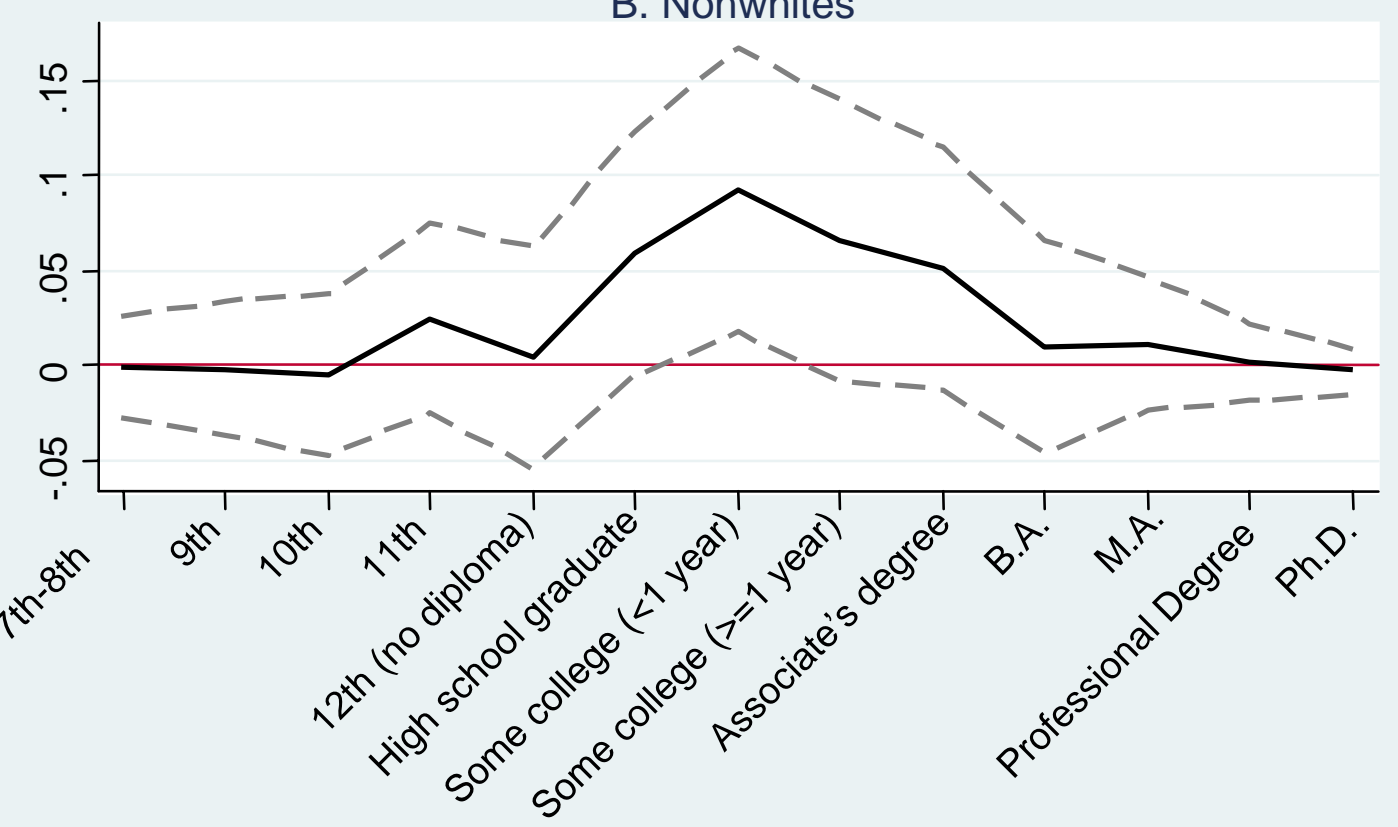

Figure 3. 2SLS Estimates of the Effects of Vietnam-era Military Service on Education - Men Born 1948-1952 

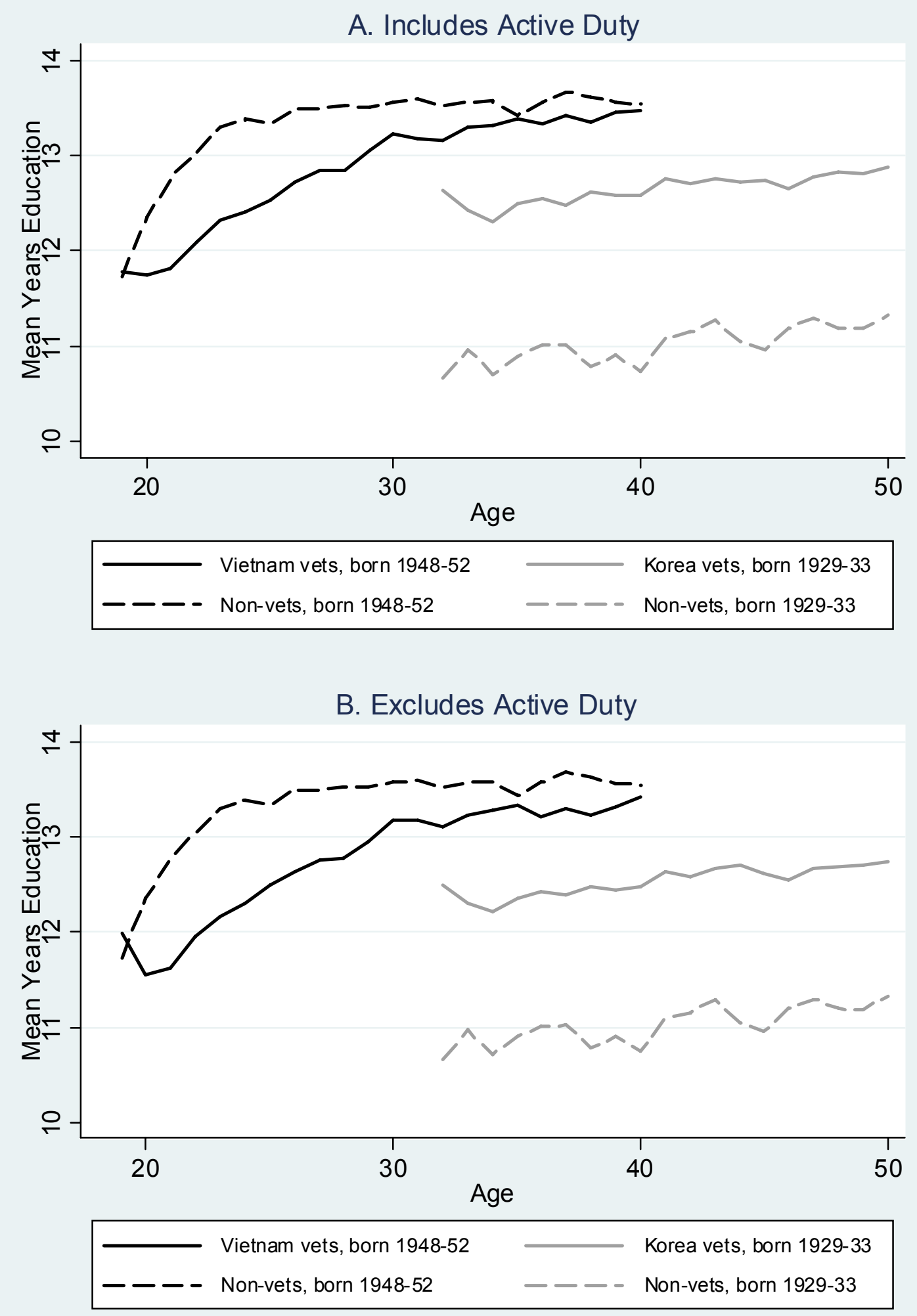

Figure 4. Average Schooling by Age, Veteran Status, and Service Era - Whites 

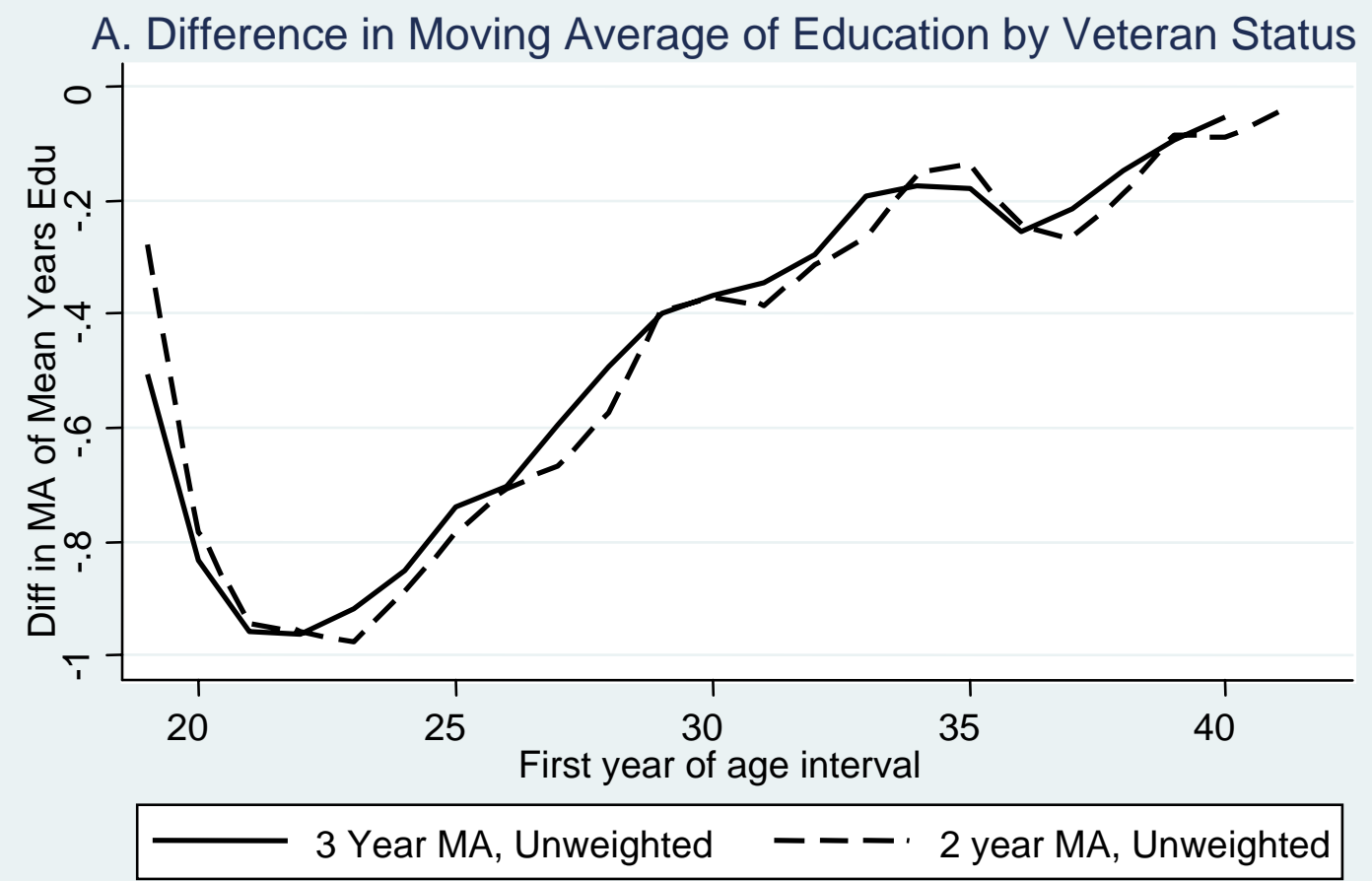

B. Difference Relative to Base Period

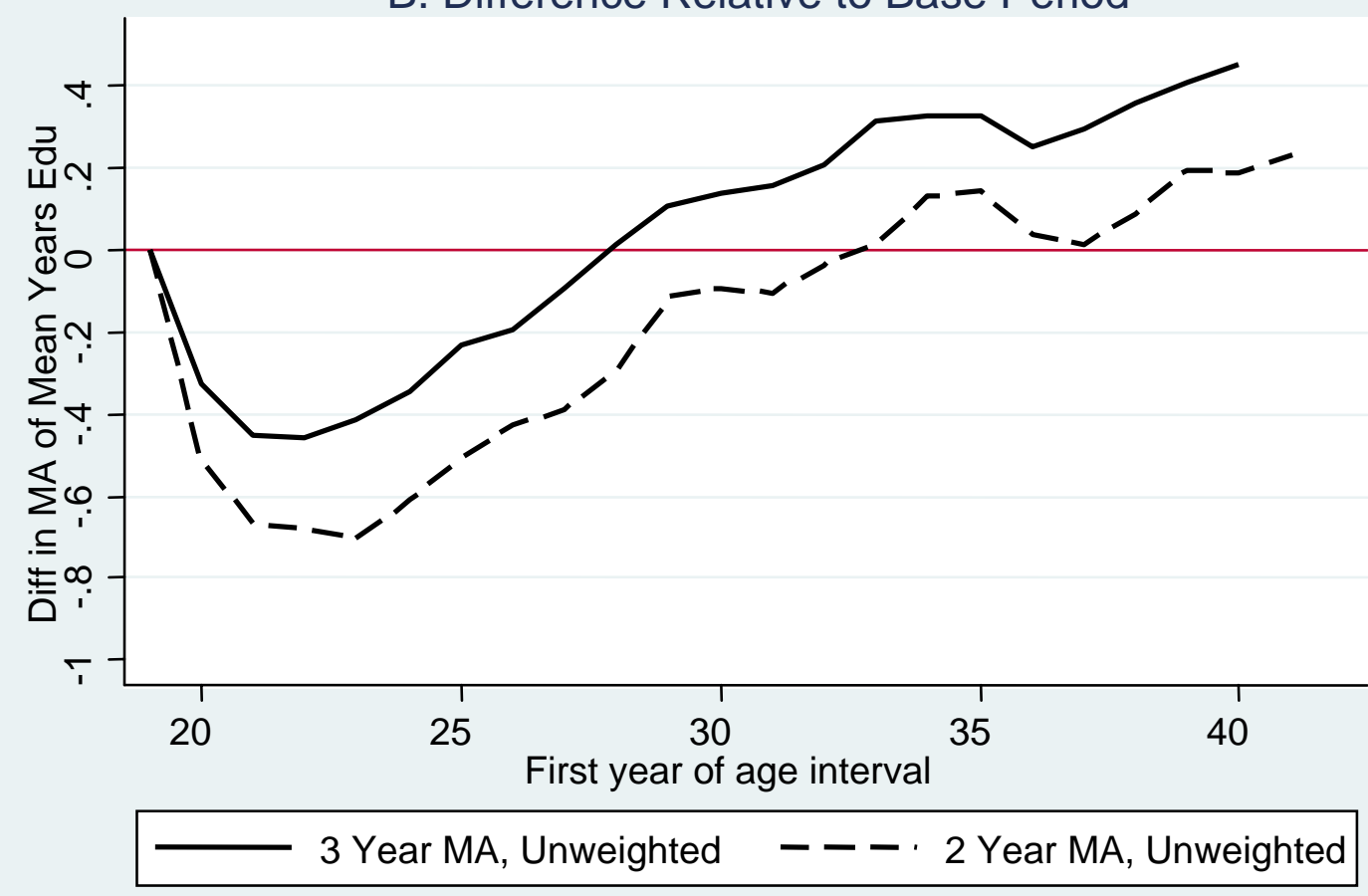

Figure 5. Schooling Differentials by Veteran Status - White Men Born 1948-1952 


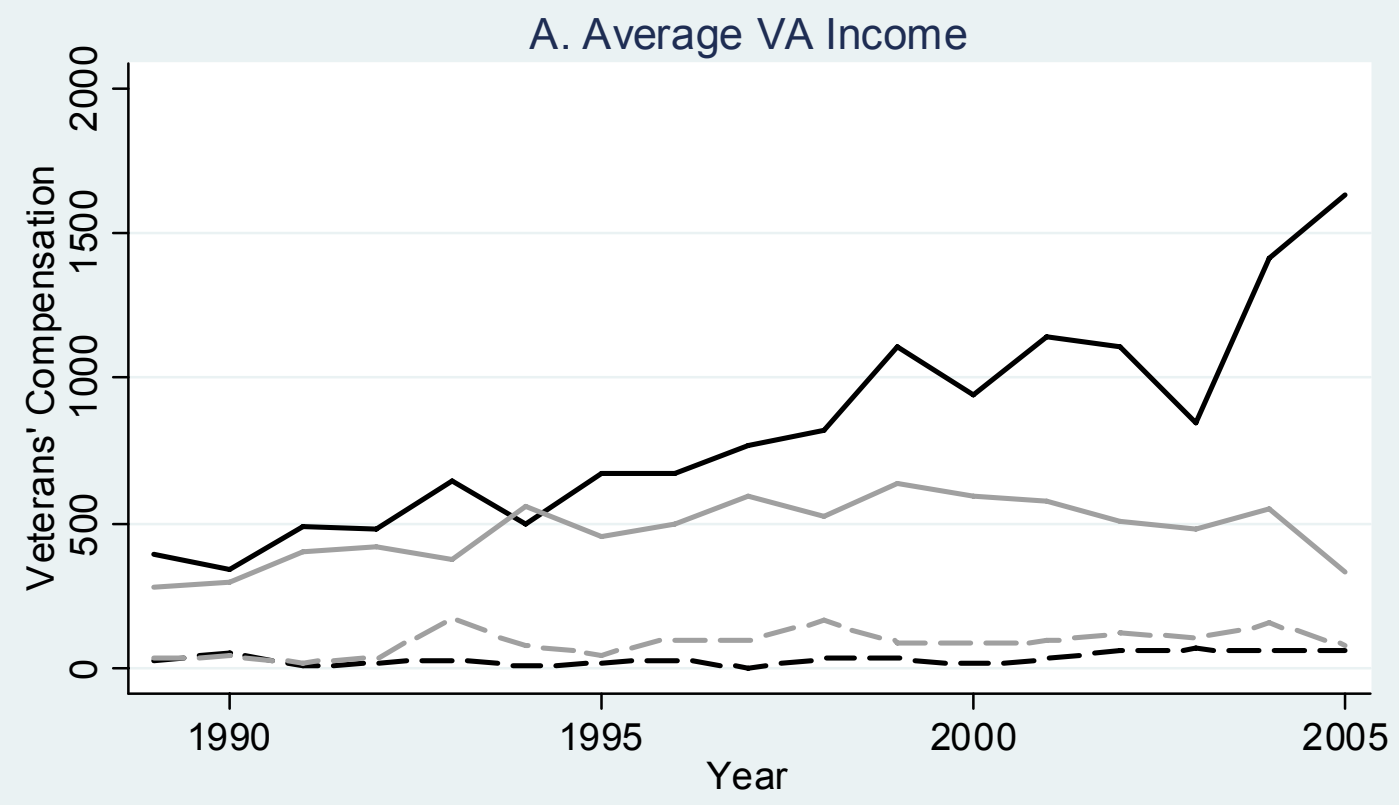

$\begin{array}{lll}- \text { Vietnam vets, born 1948-52 } & \text { Korea vets, born 1929-33 } \\ --- \text { Non-vets, born 1948-52 } & --- \text { Non-vets, born 1929-33 }\end{array}$

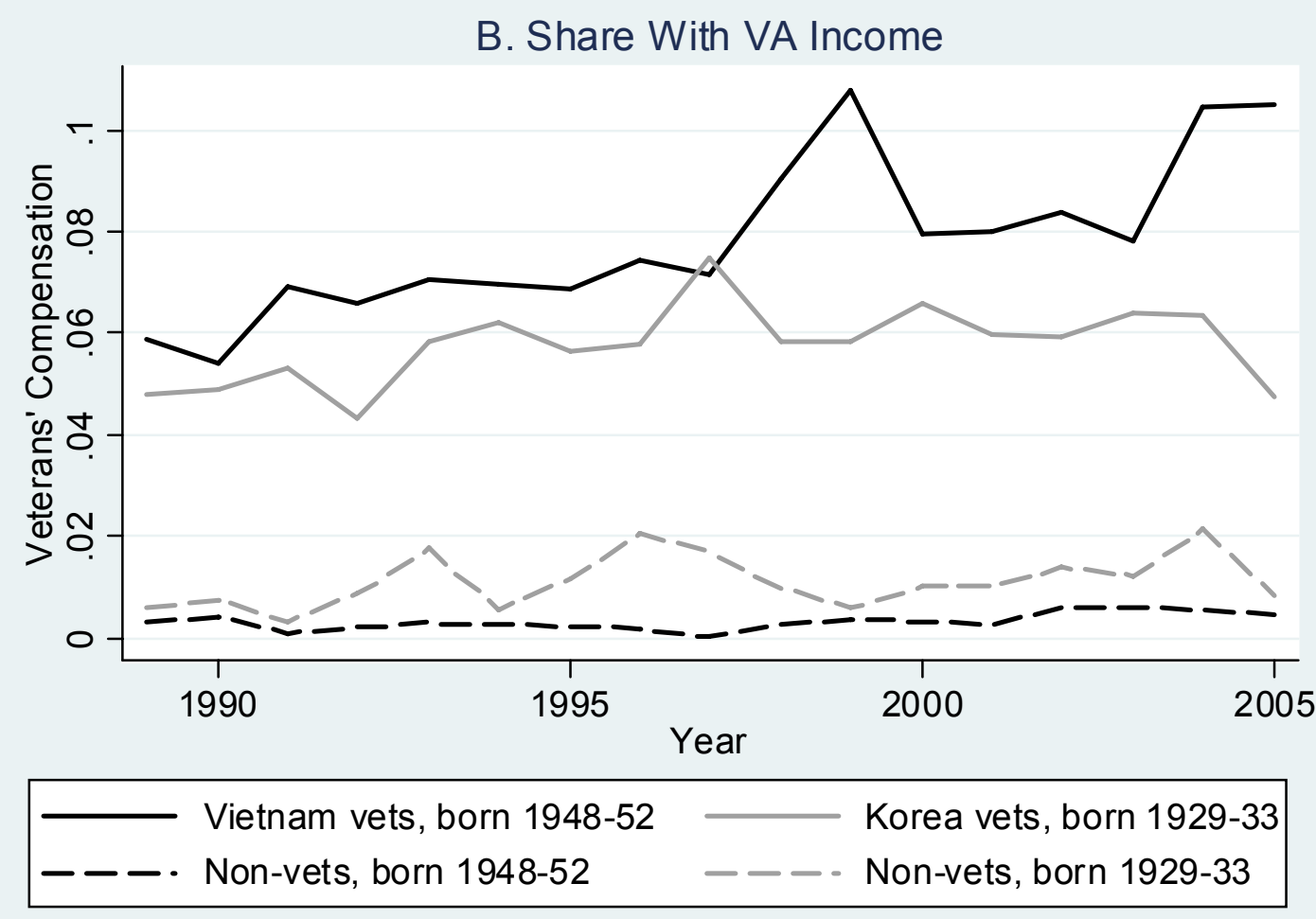

Figure 6. VA Income (Including VDC) by Year and Service Era - Whites 


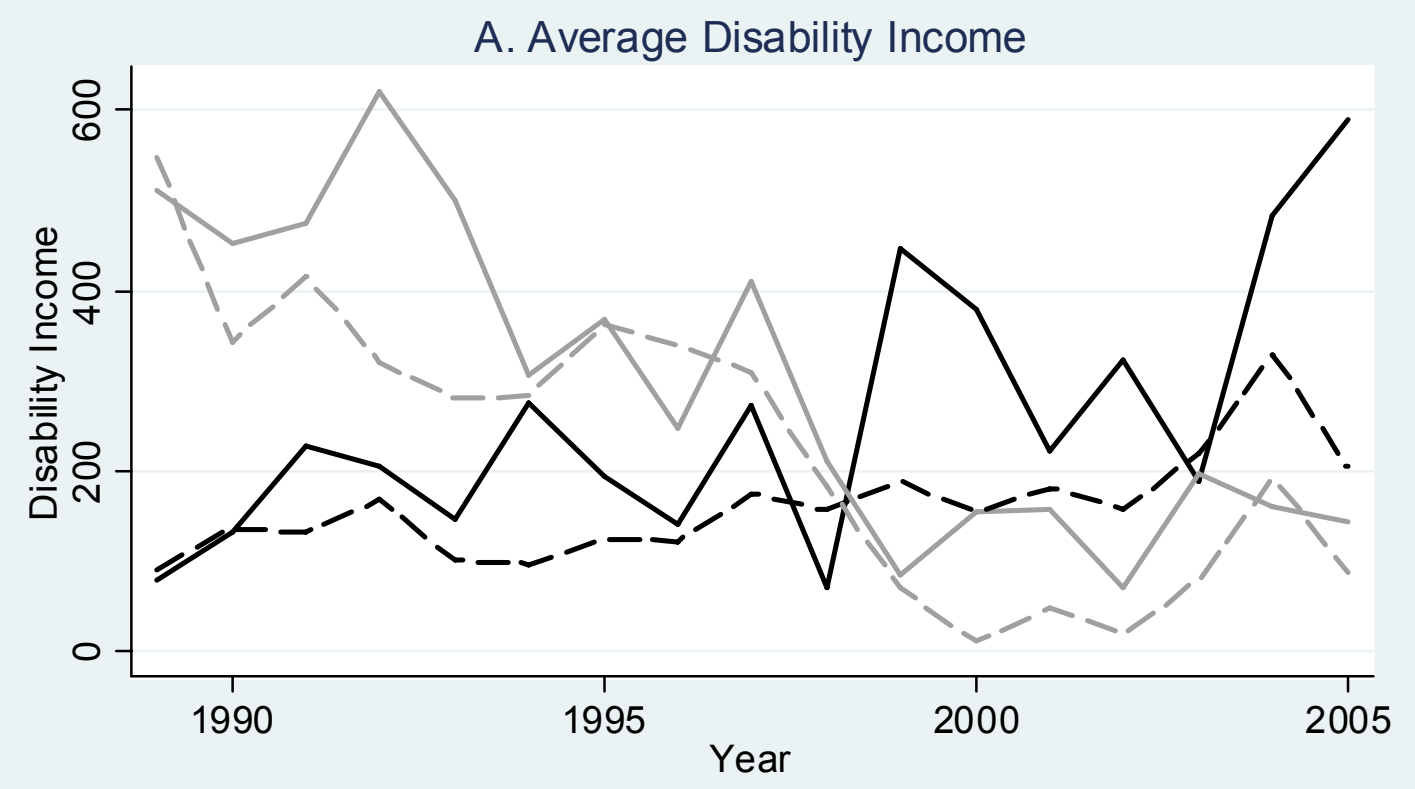

$\begin{array}{lll}- \text { Vietnam vets, born 1948-52 } & \text { Korea vets, born 1929-33 } \\ ---\cdot \text { Non-vets, born 1948-52 } & --- \text { Non-vets, born 1929-33 }\end{array}$
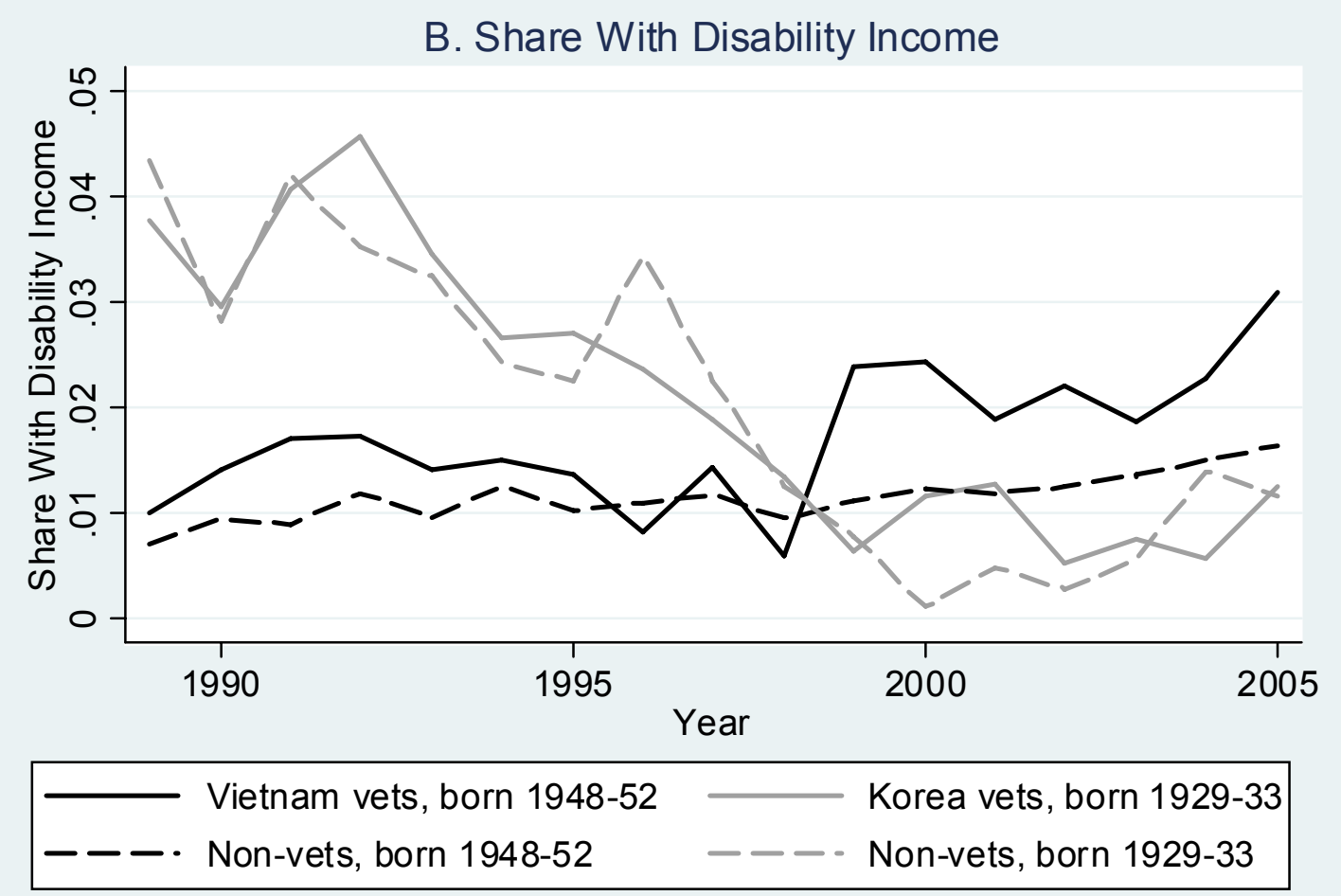

Figure 7. Non-SSA Disability Income (Including MDP) by Year and Service Era - Whites 

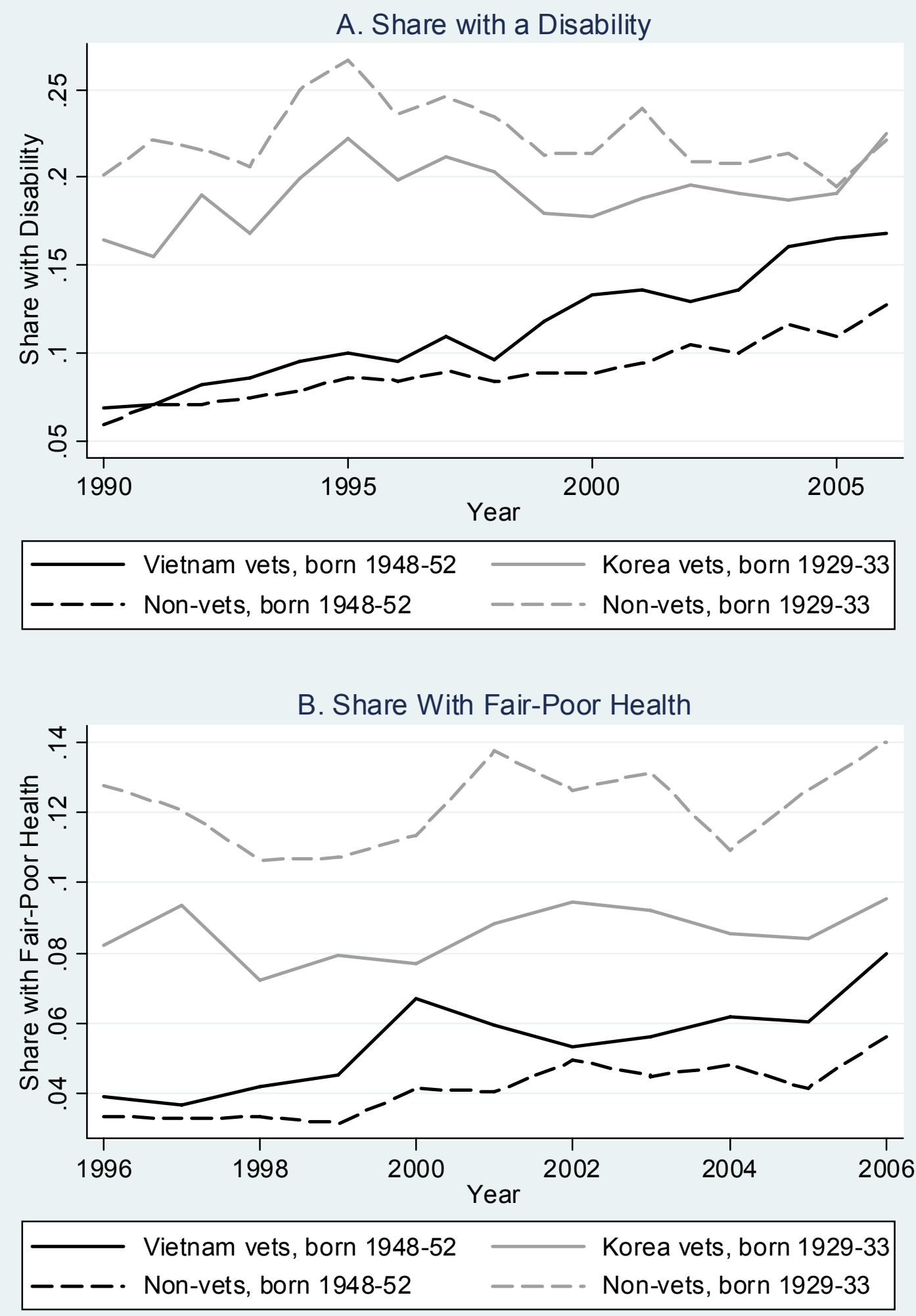

Figure 8. CPS Disability and Health Status by Year and Service Era - Whites 


\section{Appendix}

\section{A. Figures 4 and 5}

Figures 4 and 5 use data from the 1964, 1965, and 1967-1991 CPS March Demographic Supplements (the 1966 supplement does not contain veteran status). All data were downloaded from the Minnesota Population Center's Integrated Public Use Microdata Series, accessible at www.ipums.org. We include Vietnam veterans and non-veterans born 19481952 in both figures, as well as Korea veterans and non-veterans born 1929-1933 in Figure 4. Year of birth was imputed assuming men were born after the survey date. We categorized Vietnam veterans as all men born between 1948-1952 who were either veterans, as reported by the variable VETSTAT, or currently serving in the military, as reported by the variable EMPSTAT. Use of VETSTAT instead of period-of-service recodes adds a few veterans with post-Vietnam service, including some still in the military. Korea veterans were identified in an identical manner, except we used the 1929-1933 birth cohort.

Figure 4 reports mean years of education, derived from the variable HIGRADE, for veterans and non-veterans. Unlike CPS supplements from 1992 or later, the earlier supplements in our sample report years of education instead of highest degree obtained. The data are weighted using the person level weight PERWT, and collapsed over age rather than year, so at any given age, the average is derived from multiple years of data. We selected the sample so that at least three birth cohorts (i.e., 3 years of data) contribute to any given age-education observation. Figure 5 collapses the education data by age in the same way described above. We then constructed two and three year moving averages of mean years of education. The moving averages are unweighted in that each age-education observation enters with equal weight in the moving average. Panel A reports the differ-

ence between the value of the moving average for veterans and non-veterans. The $\mathrm{X}$-axis reports the first year of the age interval included in each moving average observation. (For example, the age 20 three-year moving average observation is the educational attainment of those aged 20, 21 and 22.) The same data were used to construct panel B, except that this panel shows the difference between the moving average at age 19 and subsequent values. 


\section{B. Figures 6, 7, and 8}

Figures 6, 7, and 8 use data from the 1990-2006 CPS March Demographic Supplements, also from IPUMS. We constructed birth year and selected birth cohorts in the same way as described for Figures 4 and 5. Here, however, instead of assigning service era based on birth year, we used the variable VETLAST, which reports an individual's most recent period of service. Active duty servicemen were excluded from this sample.

The disability-related income variables most relevant for veterans in the CPS are Income from Veteran Benefits (INCVET) and Income from Disability Benefits (INCDISAB). INCVET captures any income from the VA., including service related disability payments (VDC), non-disability pension payments, and educational allowances. INCDISAB information is collected only for respondents who indicate the presence of a household member with a disability. This variable includes U.S. military retirement disability pensions (MDP) but excludes disability payments from the VA or Social Security. It also covers worker's compensation, company, union, federal government civil service, state, or local government disability programs, U.S. Railroad Retirement disability, private accident or disability insurance, black lung miner's disability, and state temporary sickness payments. Amounts are in 2005 dollars.

Men who reported a disability that limits or prevents work were identified from the variable DISABWRK. This is the screening variable for INCDISAB. Men with fair or poor health were identified using the variable HEALTH, which gives self-reported health status. This variable is only available from 1996-2006.

All plots show weighted means collapsed by year using PERWT. Since income amounts refer to the previous year in the March CPS, Figures 6 and 7 run from 1989-2005. Disability and health measures refer to the time of the survey, so Panel A of Figure 8 runs from 1990-2006 and Panel B from 1996-2006. Finally, all figures discussed in this appendix include both imputed and non-imputed values. 
Table A1. Descriptive statistics for white cohorts

\begin{tabular}{|c|c|c|c|c|c|c|c|c|c|}
\hline & $1950-52$ & $1948-52$ & $1948-53$ & 1948 & 1949 & 1950 & 1951 & 1952 & 1953 \\
\hline Draft eligibility (by RSN) & .376 & .437 & .405 & .530 & .536 & .538 & .339 & .260 & .259 \\
\hline Veteran status (served in Vietnam Era) & .236 & .305 & .276 & .446 & .384 & .300 & .221 & .193 & .139 \\
\hline Post-Vietnam service & .038 & .034 & .037 & .027 & .030 & .033 & .037 & .044 & .050 \\
\hline Group quarters & .016 & .015 & .015 & .014 & .014 & .015 & .016 & .016 & .017 \\
\hline Now in military & .0027 & .0024 & .0026 & .0019 & .0022 & .0024 & .0026 & .0030 & .0032 \\
\hline Now in school & .028 & .026 & .027 & .023 & .024 & .026 & .028 & .030 & .031 \\
\hline Age & 48.2 & 49.2 & 48.7 & 51.3 & 50.2 & 49.2 & 48.2 & 47.2 & 46.2 \\
\hline \multicolumn{10}{|c|}{ A. Labor market variables } \\
\hline Employment & .861 & .855 & .857 & .843 & .850 & .855 & .861 & .865 & .867 \\
\hline Unemployment & .027 & .027 & .027 & .026 & .027 & .027 & .027 & .027 & .028 \\
\hline Not in labor force & .112 & .118 & .116 & .131 & .124 & .118 & .112 & .107 & .105 \\
\hline Usual hours worked & 41.5 & 41.2 & 41.3 & 40.5 & 40.9 & 41.2 & 41.5 & 41.7 & 41.8 \\
\hline Weeks worked & 44.8 & 44.5 & 44.6 & 43.9 & 44.2 & 44.4 & 44.8 & 45.0 & 45.1 \\
\hline Wage and salary income & 46406 & 46595 & 46521 & 46830 & 46957 & 46293 & 46592 & 46331 & 46176 \\
\hline \multicolumn{10}{|c|}{ B. Disability and disability income variables } \\
\hline Work disability & .123 & .124 & .123 & .128 & .125 & .125 & .122 & .121 & .119 \\
\hline Other disabilities & .143 & .149 & .146 & .163 & .153 & .149 & .142 & .138 & .133 \\
\hline Non-work disabilities & .070 & .074 & .072 & .082 & .077 & .074 & .070 & .068 & .065 \\
\hline Any disabilities & .193 & .198 & .196 & .211 & .202 & .199 & .192 & .189 & .184 \\
\hline Mobility & .082 & .086 & .084 & .097 & .090 & .087 & .082 & .077 & .074 \\
\hline Self care & .021 & .022 & .022 & .024 & .022 & .022 & .021 & .020 & .020 \\
\hline Physical & .051 & .052 & .052 & .055 & .053 & .053 & .051 & .050 & .049 \\
\hline Mental & .044 & .045 & .045 & .048 & .047 & .046 & .044 & .042 & .042 \\
\hline Vision or hearing & .036 & .038 & .037 & .043 & .041 & .038 & .035 & .034 & .032 \\
\hline $\begin{array}{l}\text { Other income (e.g.,VA, UI, child support, } \\
\text { alimony; incl. VDC) }\end{array}$ & 392 & 440 & 420 & 546 & 486 & 444 & 377 & 357 & 328 \\
\hline Other income $>0$ & .054 & .059 & .057 & .070 & .064 & .058 & .053 & .050 & .048 \\
\hline $\begin{array}{l}\text { Retirement/Dis. income (Retirement, survivor, } \\
\text { disability pensions; incl. MDP) }\end{array}$ & 691 & 855 & 800 & 1223 & 1007 & 787 & 673 & 621 & 541 \\
\hline Retirement income $>0$ & .043 & .051 & .048 & .068 & .059 & .049 & .043 & .038 & .036 \\
\hline \multicolumn{10}{|c|}{ C. Education variables } \\
\hline Imputed highest grade completed & 13.8 & 13.8 & 13.8 & 13.9 & 13.8 & 13.8 & 13.8 & 13.7 & 13.6 \\
\hline Years of college & 1.73 & 1.76 & 1.74 & 1.82 & 1.80 & 1.77 & 1.73 & 1.70 & 1.63 \\
\hline 9th grade + & .977 & .975 & .976 & .971 & .974 & .975 & .978 & .978 & .979 \\
\hline 10th grade + & .965 & .963 & .963 & .958 & .961 & .963 & .966 & .966 & .966 \\
\hline 11 th grade + & .948 & .946 & .946 & .942 & .943 & .945 & .948 & .949 & .948 \\
\hline 12th grade (no diploma) + & .931 & .930 & .930 & .927 & .928 & .930 & .932 & .932 & .930 \\
\hline High school graduate + & .910 & .908 & .908 & .906 & .907 & .908 & .910 & .910 & .907 \\
\hline Some college (less than 1 year) + & .655 & .659 & .654 & 667 & .667 & .662 & 657 & 646 & .629 \\
\hline 1 or more years of college (no degree) + & .582 & .588 & .582 & .599 & .598 & .591 & .584 & .571 & .551 \\
\hline Associate's degree + & .411 & .419 & .413 & .433 & .428 & .420 & .411 & .402 & .387 \\
\hline Bachelor's degree + & .333 & .341 & .335 & .358 & .350 & .342 & .333 & .324 & .309 \\
\hline Master's degree + & .135 & .140 & .137 & .151 & .145 & .139 & .135 & .131 & .122 \\
\hline Professional degree + & .051 & .052 & .051 & .054 & .053 & .051 & .051 & .050 & .047 \\
\hline N (log earnings) & 573728 & 934666 & 1134983 & 178349 & 182315 & 183435 & 191559 & 198734 & 200267 \\
\hline N (all other variables) & 696530 & 1141905 & 1382708 & 220891 & 224130 & 223984 & 232348 & 240198 & 240736 \\
\hline
\end{tabular}

Note: Sampling weights are used in all estimates and statistics. 
Table A2. Descriptive statistics for nonwhite cohorts

\begin{tabular}{|c|c|c|c|c|c|c|c|c|c|}
\hline & $1950-52$ & $1948-52$ & $1948-53$ & 1948 & 1949 & 1950 & 1951 & 1952 & 1953 \\
\hline Draft eligibility (by RSN) & .382 & .440 & .408 & .538 & .537 & .544 & .343 & .265 & .265 \\
\hline Veteran status (served in Vietnam Era) & .293 & .293 & .274 & .404 & .353 & .285 & .231 & .216 & .183 \\
\hline Post-Vietnam service & .058 & .058 & .066 & .039 & .042 & .050 & .071 & .083 & .101 \\
\hline Group quarters & .064 & .064 & .066 & .056 & .060 & .064 & .066 & .071 & .076 \\
\hline Now in military & .0025 & .0025 & .0028 & .0020 & .0019 & .0020 & .0027 & .0038 & .0039 \\
\hline Now in school & .043 & .043 & .044 & .038 & .039 & .045 & .044 & .048 & .050 \\
\hline Age & 49.2 & 49.2 & 48.6 & 51.3 & 50.2 & 49.3 & 48.2 & 47.3 & 46.2 \\
\hline \multicolumn{10}{|c|}{ A. Labor market variables } \\
\hline Employment & .665 & .662 & .663 & .657 & .654 & .662 & .666 & .669 & .670 \\
\hline Unemployment & .056 & .054 & .055 & .047 & .055 & .053 & .056 & .057 & .059 \\
\hline Not in labor force & .279 & .284 & .282 & .296 & .291 & .285 & .279 & .274 & .270 \\
\hline Usual hours worked & 32.8 & 32.6 & 32.7 & 32.1 & 32.3 & 32.6 & 32.8 & 33.1 & 33.0 \\
\hline Weeks worked & 35.9 & 35.7 & 35.7 & 35.4 & 35.4 & 35.7 & 35.8 & 36.1 & 35.9 \\
\hline Wage and salary income & 27584 & 27711 & 27561 & 28395 & 27490 & 27569 & 27508 & 27670 & 26874 \\
\hline \multicolumn{10}{|c|}{ B. Disability and disability income variables } \\
\hline Work disability & .210 & .212 & .211 & .214 & .216 & .213 & .210 & .207 & .205 \\
\hline Any other disabilities & .247 & .254 & .251 & .267 & .264 & .252 & .249 & .241 & .237 \\
\hline Non-work disabilities & .116 & .120 & .118 & .130 & .125 & .119 & .115 & .114 & .110 \\
\hline Any disabilities & .326 & .332 & .329 & .343 & .342 & .331 & .325 & .321 & .314 \\
\hline Mobility & .132 & .139 & .135 & .152 & .147 & .138 & .135 & .125 & .118 \\
\hline Self care & .040 & .042 & .041 & .046 & .044 & .041 & .041 & .038 & .038 \\
\hline Physical & .121 & .122 & .122 & .125 & .124 & .123 & .122 & .117 & .119 \\
\hline Mental & .073 & .076 & .075 & .080 & .079 & .073 & .075 & .072 & .074 \\
\hline Vision or hearing & .045 & .048 & .047 & .054 & .052 & .046 & .046 & .043 & .044 \\
\hline $\begin{array}{l}\text { Other income (e.g.,VA, UI, child support, } \\
\text { alimony; incl. VDC) }\end{array}$ & 566 & 628 & 609 & 763 & 708 & 627 & 559 & 513 & 520 \\
\hline Other income $>0$ & .072 & .078 & .076 & .091 & .084 & .075 & .070 & .070 & .068 \\
\hline $\begin{array}{l}\text { Retirement income (Retirement, survivor, } \\
\text { disability pensions; incl. MDP) }\end{array}$ & 848 & 973 & 929 & 1258 & 1117 & 916 & 867 & 765 & 731 \\
\hline Retirement income $>0$ & .065 & .071 & .068 & .085 & .077 & .068 & .065 & .062 & .058 \\
\hline \multicolumn{10}{|c|}{ C. Education variables } \\
\hline Imputed highest grade completed & 12.6 & 12.6 & 12.6 & 12.5 & 12.5 & 12.6 & 12.6 & 12.6 & 12.6 \\
\hline Years of college & 1.02 & 1.02 & 1.02 & 1.05 & 1.02 & 1.03 & 1.02 & .996 & .994 \\
\hline 9th grade + & .948 & .944 & .946 & .936 & .936 & .946 & .948 & .951 & .953 \\
\hline 10th grade + & .923 & .918 & .920 & .908 & .908 & .920 & .923 & .927 & .930 \\
\hline 11th grade + & .882 & .876 & .878 & .865 & .866 & .880 & .882 & .884 & .887 \\
\hline 12th grade (no diploma) + & .832 & .826 & .828 & .818 & .817 & .829 & .831 & .835 & .833 \\
\hline High school graduate + & .770 & .766 & .767 & .759 & .758 & .768 & .771 & .772 & .770 \\
\hline Some college (less than 1 year) + & .468 & .468 & .467 & .470 & .464 & .466 & .472 & .466 & .461 \\
\hline 1 or more years of college (no degree) + & .400 & .400 & .399 & .406 & .398 & .399 & .404 & .397 & .392 \\
\hline Associate's degree + & .226 & .228 & .227 & .235 & .229 & .231 & .226 & .221 & .221 \\
\hline Bachelor's degree + & .160 & .163 & .162 & .170 & .164 & .165 & .162 & .154 & .156 \\
\hline Master's degree + & .057 & .060 & .058 & .068 & .062 & .061 & .059 & .051 & .052 \\
\hline Professional degree + & .018 & .019 & .019 & .021 & .019 & .020 & .019 & .017 & .017 \\
\hline N (log earnings) & 71045 & 113194 & 137938 & 20286 & 21863 & 23383 & 23004 & 24658 & 24744 \\
\hline N (all other variables) & 96217 & 154810 & 188023 & 28272 & 30321 & 31942 & 31162 & 33113 & 33213 \\
\hline
\end{tabular}

Note: Sampling weights are used in all estimates and statistics. 
Table A3. Theoretical and empirical proportions drafteligible

\begin{tabular}{ccccc}
\hline \multirow{2}{*}{ Cohort } & Theoretical & \multicolumn{3}{c}{ Differential } \\
\cline { 3 - 5 } 1948 & Eligibility & All & White & Nonwhite \\
\hline \multirow{3}{*}{1949} & $195 / 366$ & -0.0015 & -0.0025 & 0.0048 \\
& {$[.533]$} & $(.0011)$ & $(.0012)$ & $(.0022)$ \\
& $195 / 365$ & 0.0018 & 0.0017 & 0.0028 \\
1950 & {$[.534]$} & $(.0011)$ & $(.0012)$ & $(.0033)$ \\
& $195 / 365$ & 0.0049 & 0.0041 & 0.0097 \\
1951 & $1.534]$ & $(.0011)$ & $(.0012)$ & $(.0032)$ \\
& $125 / 365$ & -0.0025 & -0.0030 & 0.0002 \\
1952 & $9.342]$ & $(.0011)$ & $(.0011)$ & $(.0031)$ \\
& $95 / 366$ & 0.0008 & 0.00003 & 0.0055 \\
1953 & $9.260]$ & $(.0010)$ & $(.0010)$ & $(.0028)$ \\
& $95 / 365$ & -0.0002 & -0.0011 & 0.0050 \\
& {$[.260]$} & $(.0010)$ & $(.0010)$ & $(.0028)$ \\
$\mathrm{F}(6, \infty)$ & & & & \\
$\mathrm{N}$ & & 5.07 & 4.37 & 3.24 \\
& & 1570310 & 1382287 & 188023 \\
\hline
\end{tabular}

Notes: The theoretical proportion draft eligible is reported in column 1 for each cohort. Fractions appear in brackets. Columns 2-4 report the difference between this and the empirical proportion drafteligible, with robust standard errors in parentheses. The F-statistic is for a joint test of theoretical and empirical equality for all cohorts. 


\section{References}

Anderson, T., N. Kunitomo, and T. Sawa (1982), "Evaluation of the Distribution Function of Limited Information Maximum Likelihood Estimator," Econometrica 59(4), 1009-1027.

Angrist, J. (1989), "Using the Draft Lottery to Measure the Effects of Military Service on Civilian Earnings," in Research in Labor Economics, vol. 10, edited by Ronald Ehrenberg, Greenwich, CT: JAI.

Angrist, J. (1990), "Lifetime Earnings and the Vietnam Era Draft Lottery: Evidence from Social Security Administrative Records." American Economic Review 80(3), 313-36.

Angrist, J. (1991), "The Draft Lottery and Voluntary Enlistment in the Vietnam Era." Journal of the American Statistical Association 86(415), 584-595.

Angrist, J. (1993), "The Effect of Veterans Benefits on Education and Earnings," Industrial and Labor Relations Review 46(4), 637-652.

Angrist, J., G. Imbens and D. Rubin (1996), "Identification of Causal Effects Using Instrumental Variables," Journal of the American Statistical Association 91(434), 444455.

Angrist, J. and A. Krueger (1992), "Estimating the Payoff to Schooling Using the Vietnam-Era Draft Lottery," National Bureau of Economic Research, Working paper 4067.

Angrist, J. and A. Krueger (1994), "Why Do World War II Veterans Earn More than Non-veterans?" Journal of Labor Economics 12(1), 74-97.

Angrist, J. and A. Krueger (1995), "Split-Sample Instrumental Variables Estimates of the Return to Schooling," Journal of Business and Economic Statistics 13(2), 225-235.

Autor, D. and M. Duggan (2003), "The Rise in the Disability Rolls and the Decline in Unemployment," Quarter Journal of Economics 118(1), 157-206.

Autor, D. and M. Duggan (2007), "Distinguishing Income from Substitution Effects in Disability Insurance," American Economic Review Papers and Proceedings 97(2).

Bedard, K. and O. Deschenes (2006), "The Impact of Military Service on Long-Term Health: Evidence from World War II and Korean War Veterans," American Economic Review 96(1), 176-194.

Bekker, Paul (1994), "Alternative Approximations to the Distribution of Instrumental Variable Estimators," Econometrica 62(3), 657-682. 
Berger, M. and B. Hirsch (1983), "The Civilian Earnings Experience of Vietnam-Era Veterans," Journal of Human Resources 18(4), 455-79.

Bound, J. and S. Turner (2002), "Going to War and Going to College: Did World War II and the G.I. Bill Increase Educational Attainment for Returning Veterans?" Journal of Labor Economics 20(4), pp. 784-815.

Card, D. and T. Lemieux (2001), "Going to College to Avoid the Draft: The Unintended Legacy of the Vietnam War," The American Economic Review 91(2), 97-102.

Dobkin, C. and R. Shabani (2006), "The Long Term Health Effects of Military Service: Evidence from the National Health Interview Survey and the Vietnam Era Draft Lottery," University of California at SantaCruz, Department of Economics, mimeo.

Duggan, M., R. Rosenheck and P. Singleton (2006), "Federal Policy and the Rise in Disability Enrollment: Evidence for the VA's Disability Compensation Program," National Bureau of Economic Research Working paper 12323.

Eisenberg, D. and B. Rowe (2007), "Effects of Military Service in Vietnam on Smoking Later in Life," Department of Health Management and Policy, University of Michigan, mimeo.

Eitelberg, M., J. Laurence, B. Waters and L. Perelman (1984), "Screening for Service: Aptitude and Education criteria for Military Entry," Washington, DC: Office of the Assistant Secretary of Defense (Manpower, Installations and Logistics), September.

Goldberg, J., M. Richards, R. Anderson, and M. Rodin (1991), "Alcohol Consumption in Men Exposed to the Military Draft Lottery: A Natural Experiment," Journal of Substance Abuse 3, 307-313.

Griliches, Z. and W.M. Mason (1972), "Education, Income, and Ability," Journal of Political Economy 80(3, Part II), S74-S103.

Hausman, J., W.K. Newey, and T. Woutersen (2006), "IV Estimation with Heteroskedasticity and Many Instruments," MIT Department of Economics, memo, November.

Hearst, N., J. Buehler, T. Newman, and G. Rutherford (1991), "The Draft Lottery and AIDS: Evidence Against Increased Intravenous Drug Use by Vietnam Veterans," American Journal of Epidemiology 134(5), 522-525.

Hearst, N., T. Newman and S. Hulley (1986), "Delayed Effects of the Military Draft on Mortality: A Randomized Natural Experiment," mimeo, New England Journal of Medicine 314(10), 620-24. 
Heckman, J.J, L. Lochner, and P. Todd (2005), "Earnings Functions, Rates of Return and Treatment Effects: The Mincer Equation and Beyond," IZA Discussion Paper No. 1700, August.

Henderson, D. (2005), "The Role of Economists in Ending the Draft," Econ Journal Watch 2(2), 362-376.

Imbens, G., and J. Angrist (1994), "Identification and Estimation of Local Average Treatment Effects," Econometrica 62(2), 467-475.

Imbens, G. and W. van der Klaauw (1995), "Evaluating the Cost of Conscription in the Netherlands," Journal of Business and Economic Statistics 13(2), 207-215.

Jaeger, D. (1997), "Reconciling the Old and New Census Bureau Education Questions: Recommendations for Researchers," Journal of Business and Economic Statistics 15(3), 300-309.

Lemieux, T. and D. Card (2001), "Education, Earnings And The Canadian G.I. Bill," Canadian Journal of Economics 34(2), 313-344.

Newey, W. (1990), "Efficient Instrumental Variables Estimation of Nonlinear Models," Econometrica 58(4), 809-837.

Oi, W. (1967), "The Economic Cost of the Draft," American Economic Review 57(2),3962 .

Schwartz, S. (1986), "The Relative Earnings of Vietnam and Korean-Era Veterans," Industrial and Labor Relations Review 39(4), 564-72.

Seftor, N.S. and S.E. Turner (2002), "Back to School: Federal Student Aid Policy and Adult College Enrollment," Journal of Human Resources 37(2), 336-352.

Selective Service System, Office of Public Affairs (1970), A Short History of the Selective Service System, Washington: USGPO.

Selective Service System, Office of Public Affairs (1986), Semiannual Report of the Director of Selective Service, Washington: USGPO.

Seltzer, C. and S. Jablon (1974), "Effects of Selection on Mortality," American Journal of Epidemiology 100(5), 367-372.

Stanley, M. (2003), "College Education and the Midcentury GI Bills," Quarterly Journal of Economics 118(2), 671-708

Turner, S. and J. Bound (2003), "Closing the Gap or Widening the Divide: the Effects of the G.I. Bill and World War II on the Educational Outcomes of Black Americans," Journal of Economic History 63(1), 145-177. 
U.S. Bureau of the Census (2005), Technical Documentation: Census of the Population, 2000: Public use Microdata Sample, Washington: US Bureau of the Census.

U.S. Congressional Budget Office (1978), the Congress of the United States "Veteran's Educational Benefits: Issues Concerning the GI Bill," October.

VA Office of Inspector General (2005), "Review of State Variances in VA Disability Compensation Payments," Department of Veterans Affairs Office of Inspector General, Report No. 05-00765-137 Washington, DC.

Veterans Benefits Administration (2000), "Annual Benefits Report for Fiscal Year 1999," Washington, DC: Veterans Benefits Administration.

Veterans Benefits Administration (2002), "Annual Benefits Report for Fiscal Year 2001," Washington, DC: Veterans Benefits Administration. 